\title{
Metathesis in Phonological Theory: The Case of Leti ${ }^{1}$
}

\author{
Elizabeth Hume \\ Ohio State University \\ ehume@julius.ling.ohio-state.edu \\ January 1997
}

\begin{abstract}
This paper examines two types of metathesis in the Austronesian language, Leti. The first is motivated by a requirement that all phrases end in a vowel, and the second, by syllable well-formedness conditions: syllables have onsets and tautosyllabic consonant clusters are avoided.

The analyses in this paper are cast within the framework of Correspondence Theory (CT), and bear directly upon the constraint LINEARITY, which penalizes the reversal of precedence relations among segments in a string. Through the interaction of LINEARITY with syllable structure and phrasal alignment constraints, a unified account of the Leti facts is provided. Further, it is argued that violations of LINEARITY are evaluated in a gradient manner. Constraints on LINEARITY are also shown to be needed to account for the observation that it is consistently the final vowel and consonant of a given morpheme that metathesize, even though metathesis involving other segments would result in equally well-formed Leti words.

This study is of significance not only with respect to the theoretical implications it has for Correspondence Theory and, in particular, the constraint LINEARITY, but in addition, for further advancing our understanding of metathesis which is not only poorly understood, but perhaps misperceived as a marginal or even nonexistent process. This view is contradicted by Leti metathesis which is not only regular and productive, but may be driven by purely phonological considerations.
\end{abstract}

1 Aspects of this work were presented at the University of Utrecht (OTS), the University of Massachusetts, Amherst, the Montreal-Ottawa-Toronto phonology workshop, and to the phonetics/phonology discussion group at the Ohio State University. I would like to thank the members of those audiences for their comments and suggestions, in particular, Jill Beckman, Mary Bradshaw, René Kager, John Kingston, John McCarthy, David Odden, Joe Pater, Glyne Piggott, Keren Rice, Elisabeth Selkirk and Wim Zonneveld. My gratitude also to Juliette Blevins, Mike Cahill, Abigail Cohn, Aone van Engelenhoven, Harry van der Hulst, Jennifer Muller, Robert Poletto and Sam Rosenthall for valuable comments and discussion relevant to this study. 


\section{Introduction}

Metathesis, or the process by which the linear ordering of segments switches, is a poorly understood process. While metathesis is attested in a wide range of languages, ${ }^{2}$ as a synchronic process it is often considered to be marginal and, as a result, relatively little attention has been given to it in the phonological literature, ${ }^{3}$ particularly in comparison to such well-studied processes such as assimilation. In both sound change and synchronic phonological systems, assimilation is a widespread phenomenon, while metathesis on the other hand, though frequently regular, can be limited in its scope, affecting only a subset of forms or morphological classes of a given language. A partial explanation of these observed differences between metathesis and assimilation stems, as noted by Kiparsky (1995), from the motivation behind each: assimilation tends to be production (articulatorily) driven, while metathesis is perception (acoustically) driven. Articulatorydriven processes, in contrast to perceptually-driven ones, generally develop due to physiological constraints on the vocal tract apparatus and, as a result, tend to be more automatic and hence, widespread. As such, it is not surprising to find metathesis affecting only a restricted portion of a given phonological system.

A further reason for the limited attention given to metathesis in phonological theory stems from the observation that metathesis is often used as a means of distinguishing between morphological classes. As such, one might argue, metathesis lies outside the realm of phonology and, consequently, phonological theory need not provide an account of it. However, as McCarthy's (1995) recent reanalysis of Rotuman metathesis convincingly shows, even in cases of metathesis which serve to distinguish morphological classes, prosodic requirements play a central role in determining the particular shape of the metathesis alternants. An even stronger case would be one in which metathesis is not only pervasive and regular, but driven by purely phonological considerations.

Precisely such a case is found in Leti, an Austronesian language spoken on the island of Leti, off the eastern tip of Timor. Of interest is the observation that Leti displays two types of metathesis, both of which are pervasive and productive: the first, motivated by phrasal requirements, and the second, by purely phonological conditions. The latter is illustrated in (1a), where the first morpheme ends in a consonant/vowel before a following consonant cluster or consonant/glide sequence. Before a morpheme beginning with a simple onset, on the other hand, the final segments of the first morpheme occur in the reverse order. Phrase-final metathesis is exemplified in (1b), where a morpheme ends in a consonant/vowel sequence. Comparing these with their phrase-medial counterparts to the right, it will be observed that these same morphemes surface, once again, with the consonant and vowel in reverse position when followed by a morpheme-initial simple onset. $^{4}$

2 While cases of diachronic metathesis are too numerous to list here, some examples of languages with synchronic cases of consonant/vowel metathesis include Basaa, Bedouin Arabic, Clallam, Kwara'ae, Leti, Lummi, Maltese, Mingrelian, Mutsun, Incahuasi Quechua, Romansch, Rotuman, Saanich, Sierra Miwok.

Examples of consonant/consonant metathesis are attested in languages such as Deg, Chawchila Yokuts, Elmolo, Mokilese, Palauan, Kui, Sidamo, Rendille, Turkana, Modern Hebrew, Old Spanish, Balangao, Hanunoo, Wichita. See Hume, 1996b for references and discussion.

3 Previous phonological analyses of metatheses include Hume, 1990, 1995; Besnier, 1987; McCarthy, 1989, 1995; Poletto, 1993; Smith, 1984; Stonham, 1990; van der Hulst \& van Engelenhoven, 1994.

4 Before a vowel-initial morpheme, the final consonant of the preceding morpheme syllabifies as onset 


\begin{tabular}{|c|c|c|c|}
\hline & ukra ppalu & 'finger,toe + bachelor $=$ index finger' & /ukar + ppalu/ \\
\hline & ukra mwani & 'finger,toe + man = middle finger' & /ukar + muani/ \\
\hline cf. & $\begin{array}{l}\text { ukar lavna } \\
\text { Phrase-final }\end{array}$ & $\begin{array}{l}\text { 'finger,toe }+ \text { big }=\text { thumb, big toe' } \\
\text { cf. Phrase-medial }\end{array}$ & /ukar + lavan/ \\
\hline & urnu & urun moa 'breadfruit + Moanese' & /urun + moa/ \\
\hline & bubru & bubur vetra $\quad$ 'porridge + maize' & /bubur + vetar/ \\
\hline & ßu:ra & ßuar lavna 'mountain, to be big' & $/ \beta u a r+$ lavan/ \\
\hline
\end{tabular}

One of the central goals of this paper is to elicidate the conditions under which metathesis occurs in Leti. As will be shown, phrase-final metathesis occurs as a means of satisfying a phrasal requirement that all morphemes end in a vowel, while phrase-medial metathesis serves to satisfy syllable structure requirements: syllables must have onsets and consonant clusters are avoided. These syllable structure conditions are also instrumental in accounting for a range of other forms in the language.

Drawing on recent work in phonological theory, the analyses in this paper are cast within the framework of Correspondence Theory (CT), an offspring of Optimality Theory (OT). As in OT, in Correspondence Theory a given surface form is derived from an input by means of a universal set of ranked constraints, rather than rules (see e.g. Prince \& Smolensky, 1993; McCarthy \& Prince, 1993; McCarthy \& Prince, 1995). In CT, however, greater emphasis is placed on relations between input and output elements. As a means of formalizing these relations, new families of constraints have been introduced which penalize lack of faithfulness between input and output.

Among these new constraints is LINEARITY, given in (2) (McCarthy, 1995; McCarthy \& Prince, 1994, 1995; see also Hume, 1994b) which penalizes the reversal of precedence relations among segments in a string. As such, forms displaying metathesis incur a violation of LINEARITY.

(2) LINEARITY: "No Metathesis" (McCarthy \& Prince, 1995)

$\mathrm{S}_{1}$ is consistent with the precedence structure of $\mathrm{S}_{2}$, and vice versa.

Let $x, y \in S_{1}$ and $x^{\prime}, y^{\prime} \in S_{2}$.

If $\mathrm{x} \Re \mathrm{x}^{\prime}$ and $\mathrm{y}^{\prime} \mathrm{y}^{\prime}$, then

$\mathrm{x}<\mathrm{y}$ iff $\neg\left(\mathrm{y}^{\prime}<\mathrm{x}^{\prime}\right)$.

The analyses of Leti metathesis in this paper build upon the account of Rotuman metathesis presented in McCarthy 1995. As McCarthy shows, the subordination of LINEARITY to other constraints forces a change in the linear ordering of segments, hence, metathesis. Thus, like all constraints, LINEARITY may be violated as a means of satisfying other more highly-ranked constraints. Further extending this approach, our account of Leti reveals that the interaction of LINEARITY with syllable structure and phrasal alignment constraints provides a unified account of Leti metathesis. In addition, violations of LINEARITY are argued to be evaluated in a gradient manner. That is, each precedence reversal in a given form incurs a violation of the constraint. As will be shown, this predicts, all else being equal, that minimal violations of LINEARITY will

of the following syllable. See section 2.2. for related discussion or Hume, 1997, for a detailed account. 
always be optimal. Thus, in Leti, metathesis may occur only once within a given form. By comparison, in the Costanoan language Mutsun, metathesized forms may surface with more than one LINEARITY violation, forced by the need to satisfy additional highly ranked constraints. Also of interest to the study of metathesis is the observation that in Leti, it is consistently the final vowel and consonant of a given morpheme that metathesize, even though metathesis involving other segments would result in equally well-formed Leti words. As will be shown, Leti metathesis is constrained by the requirement that the metathesized vowel may not intrude between tautomorphemic segments. Rather, the vowel systematically shifts to the outer edge of a morpheme. This observation parallels that noted with respect to vowel epenthesis (Kenstowicz 1994) and is shown to be accounted for using similar constraints.

While the greater part of this work focusses on a Correspondence Theoretic account of Leti metathesis, the final section compares this analysis to one within a nonlinear rulebased approach. As will be argued, a rule-based account of metathesis is not only more complex in terms of the formalism used, but is unable to generalize to other cases of metathesis, in particular, consonant/consonant metathesis.

The importance of this study of Leti metathesis goes beyond its theoretical implications for Correspondence Theory and, in particular, the constraint LINEARITY. It is equally important for further advancing our understanding of metathesis which, as noted above, is not only poorly understood but perhaps misperceived as a marginal or even nonexistent process (see e.g. Webb 1974). This view is flatly contradicted by Leti metathesis which is not only regular and productive, but may be driven by purely phonological considerations.

The organization of this paper is as follows. After introducing relevant background information concerning the Leti language, our analyses begin with an examination of syllable structure conditioned metathesis. Section 2.1 focusses on the avoidance of complex syllable margins as the impetus for change by metathesis, while section 2.2. discusses the role of onsetless syllables as motivation. Forms displaying compensatory lengthening effects are treated in section 2.3. After a brief look at phrase-final metathesis in section 2.4, our discussion shifts to two issues raised by the preceding analyses. First, in section 3 , the observation that metathesis only involves the final vowel and consonant of a morpheme is examined. Following this, the discussion centers around the proposal that LINEARITY violations are gradient in nature. A comparison of the proposed analyses with a nonlinear rule-based account appears in section 5 .

\subsection{Background Assumptions}

We turn now to some relevant background information concerning Leti. The data in this study are drawn primarily from the grammar of van Engelenhoven 1994, although additional data have been provided through consultations with Aone van Engelenhoven (p.c.), a native speaker of Leti. While discussion of syllable structure will occur at various points throughout the paper it is perhaps useful to point out that there are no diphthongs in the language; each transcribed vowel is a syllable peak. ${ }^{5}$ Thus, $a i$ 'wood' is comprised of two syllables. For reference, the underlying segmental inventory is included in (3).

5 Identical adjacent vowels are realized as long, except word-finally. 


\section{HUME/METATHESIS}

(3)

\begin{tabular}{|c|c|c|c|c|c|}
\hline Segn & inventory & & & & \\
\hline & labial & dental & alveolar & velar & $\mathrm{i}$ \\
\hline stop & $\mathrm{p}, \mathrm{pp}$ & $\mathrm{t}, \mathrm{tt}$ & $\mathrm{d}, \mathrm{dd}$ & $\mathrm{k}, \mathrm{kk}$ & $\mathrm{e}$ \\
\hline cont. & $\beta / v^{6}$ & s, ss & $\mathrm{r}, \mathrm{rr}$ & & $\varepsilon$ \\
\hline son. & $\mathrm{m}, \mathrm{mm}$ & $\mathrm{n}, \mathrm{nn}$ & 1,11 & & \\
\hline
\end{tabular}

A few comments concerning stress may also prove useful. As illustrated in (4), word stress falls on the penultimate syllable. Coda consonants are stress-insensitive.

$\begin{array}{llll}\text { spóu } & \text { 'kind of boat' } & \text { pdudúklu } & \text { 'bubbling' } \\ \text { ppúna } & \text { 'nest' } & \text { tußúri } & \text { 'Charonia tritonis' } \\ \text { pénta } & \text { 'grass' } & \text { marsína } & \text { 'machine' } \\ \text { polí:sa } & \text { 'police' } & \text { kúnsi } & \text { 'key' } \\ \text { karsyəńa } & \text { 'pumpkin' } & \text { meśra } & \text { 'teacher' }\end{array}$

When words and morphemes are concatenated within an utterance, main stress falls on the rightmost morpheme with secondary stress generally occurring on alternating syllables preceding the main stress (suffixes are typically extraprosodic, however, and long vowels are always stressed). Representative examples appear in (5).
a. p por̀salyoŕa
'seaside gate'
b. nayàpiloĭ
'he makes the proa'
c. kaßàlkißnútna
'iron frying pan'
d. mà: ${ }^{\mathrm{W}}$ oryóri
'bird + buffalo = crow'
e. rò:nénu
f. mà:nwá:na
'they eat turtle'
g. nßaltyáni
'chick'
h. matrúma
'he digs'
*[nßàltyáni]
i. rimota
'master of the house' *[màtrúma]
j. pup ${ }^{\text {éna }}$
'turtle'
'dragon fly's chrysalis'

While long vowels attract secondary stress, as evidenced by ( $5 \mathrm{~d}-\mathrm{f})$, closed syllables do not. Rather, as shown in $(5 \mathrm{~g}-\mathrm{h})$, they pattern with monomoraic open syllables $(5 \mathrm{i}-\mathrm{j})$, supporting our assumption that consonants in Leti are non-moraic. See Hume, Muller \& van Engelenhoven 1996 for additional evidence and discussion concerning the nonmoraicity of consonants (including geminates) in Leti.

As a final point, it is important to note that both consonant- and vowel-final forms are assumed to be underlying in this work. This approach is in contrast to that assumed in van Engelenhoven 1994, 1995 where all forms are taken to be underlyingly vowel-final. These differences in assumptions bear directly on the analyses in this paper and, in particular, as concerns metathesis. In the present paper, all forms which undergo metathesis are underlyingly consonant-final. Thus, underlying /lout/, /urun/ are realized as lo:tu 'servant', urnu 'breadfruit' phrase-finally, and before a /CCV/- or /CVV/-initial

$6[\beta]$ and $[\mathrm{v}]$ are in free variation and are the only consonants in the language which do not have geminate counterparts (see Hume, Muller \& van Engelenhoven 1996 for discussion of Leti geminates). 
morpheme, but remain unchanged before a /CV/-initial form, e.g. lout de 'servant once' Conversely, metathesis never affects vowel-final forms. Consequently, vowel-final lopu /lopu/ 'dolphin' remains unchanged phrase-finally (cf. /lout/ lo:tu).

An account which assumes that all forms are underlyingly vowel-final is problematic for a number of reasons. The first relates to the analysis of metathesis. In the ALL-VFINAL-APPROACH, it is assumed that metathesis applies only before $\mathrm{CV}$-final morphemes. Thus, in this alternative approach, lo.ut de would be derived from underlying /lo:tu + $d e /$, and kunis de would come from /kunsi $+d e /$. What this approach fails to account for, however, is why vowel-final forms such as $/$ lopu $+d e /$ fail to metathesize, i.e. *lo.up de, even though the output is a well-formed sequence (cf. lout de 'servant once'). Rather, the final vowel is realized as a secondary articulation or deletes (see Hume, 1997). In the approach taken in this paper, morphemes are divided into consonant-final and vowel-final stems, e.g. /lout/ vs. /lopu/. Only consonant-final morphemes undergo metathesis: first, to satisfy a vowel-final phrasal requirement, and second, to satisfy syllable structure conditions.

Perhaps an even stronger argument against assuming that all morphemes are underlyingly vowel-final relates to the observation that the distribution of long vowels is completely predictable in Leti: long vowels only occur in morphemes which alternate with vowel hiatus forms, e.g. lo.ut 3 lo:tu 'servant (phrase-medial/phrase-final)'; pu.a, ри:ти 'betel/your betel'. Were long vowels part of the underlying inventory, as would be assumed by positing an underlying form such as /lo:tu/, we would expect to find long vowels in other positions as well. Conversely, by assuming an underlying form such as /lout/, vowel length arises when the final vowel is deleted or transposed; that is, as will be shown, vowel length is analyzed as a compensatory lengthening effect, a common process cross-linguistically.

\section{Syllable Structure Motivated Metathesis}

Our study of metathesis in Leti begins with an examination of metathesis motivated by strictly phonological conditions, in particular, syllable structure. As can be seen in (6a), preceding a morpheme-initial consonant cluster or /CVV/ sequence, the ordering of morpheme-final segments is consonant + vowel. Under the assumption that these initial morphemes are underlying consonant-final, metathesis is observed in this context. Note that when the first morpheme ends in $/ \mathrm{VVC} /$, metathesis is accompanied by a compensatory lengthening effect; that is, the first vowel is realized as long, while in the nonmetathesized variant, the vowel surfaces as short. To anticipate the discussion in section 2.3, in metathesis only the segmental quality of a vowel shifts position; the position of the vowel's mora remains unchanged. As a result, the penultimate stem vowel spreads to the mora left behind by the metathesized vowel resulting in a compensatory lengthening effect, e.g. /maun/ -> ma:nu 'bird'.

That metathesis is at play receives support from the observation that before a morpheme-initial CV sequence, as in (6b), the consonant-final alternant surfaces, e.g. ukarlavna 'thumb, big toe', cf. ukramwani 'middle finger'. Thus, in (6b), no metathesis applies and instead the surface form corresponds to the underlying consonant-final form. 


\section{HUME/METATHESIS}

(6)a.

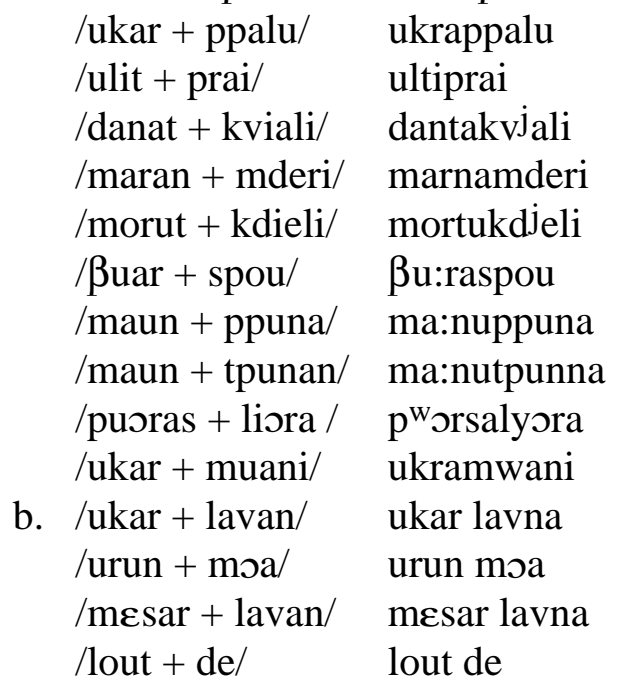

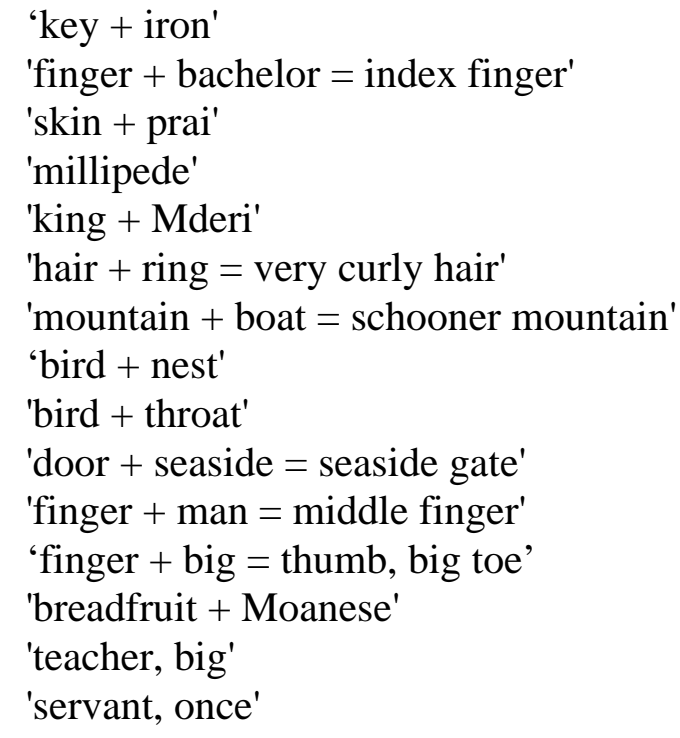

All cases of metathesis observed above are motivated by syllable well-formedness conditions. With respect to metathesis before an initial consonant cluster, the avoidance of tautosyllabic consonant clusters provides the impetus for change, while before a /CVV/-initial sequence, the avoidance of onsetless syllables is key. We begin by considering metathesis before consonant clusters.

\subsection{The Avoidance of Complex Syllable Margins}

Metathesis before a consonant cluster serves to avoid a complex syllable margin. Thus, the surface syllabification of a form such as /ulit prai/ is claimed to be ul.tip.ra.i with the first consonant of the second morpheme syllabifying as coda of the preceding syllable. Were metathesis not to apply, we would expect the initial consonant of the second morpheme to syllabify as part of a complex syllable margin, e.g. *u.lit.pra.i or *u.litp.ra.i.

The claim that syllable structure is at issue receives support from the observation that before a morpheme beginning with a simple onset, as in (7), a consonant-final morpheme does not undergo metathesis. Rather, the surface form corresponds to the underlying form. ${ }^{8}$ Note also that despite the fact that the inputs of (6a) and (7) differ, the acrossmorpheme syllabification of the output in both is identical: VC.CV. That is, syllable margins maximally contain a single consonant.

\footnotetext{
7 Throughout this paper I assume that the final morpheme in a sequence occurs in phrase-final position. Consequently, phrase-final metathesis affects underlyingly consonant-final morphemes, as outlined in section 2.4.

8 Before a vowel-initial morpheme, the final consonant of a morpheme syllabifies as onset of the following syllable. Since phrase-medially word-final open syllables are prohibited, a final high vowel of the preceding morpheme is realized as a secondary articulation on an adjacent prevocalic consonant, provided that the following vowel is not also high, e.g. /tikil + erun/ tik.lyer.nu 'to kick + downwards'. Otherwise, the high vowel of the first morpheme deletes, e.g. /urun + ipar/ ur.nip.ra 'breadfruit + slice'. Similarly, a final nonhigh vowel deletes when it would otherwise occur in a word-final open syllable. For detailed discussion concerning these changes, see Hume 1997.
} 


\section{HUME/METATHESIS}

(7)

$\begin{array}{lll}\text { /urun/ } & \text { urun moa } & \text { 'breadfruit + Moanese' } \\ \text { /mesar/ } & \text { mesar lavna } & \text { 'teacher, big' } \\ \text { /lout/ } & \text { lout de } & \text { 'servant, once' } \\ \text { /aur/ } & \text { aur di } & \text { 'lime, now' } \\ \text { /Buar/ } & \text { Buar lavna } & \text { 'highest mountain' } \\ \text { /laar/ } & \text { la:r wa:ra } & \text { 'squamosa root' } \\ \text { /pokar/ } & \text { pokar ne } & \text { 'their leanness' }\end{array}$

The avoidance of complex syllable margins also figures into the realization of vowelfinal forms. As shown in (8a), before a morpheme beginning with a consonant cluster, the final vowel of the preceding morpheme is realized as a vowel. Conversely, in (8b), it can be seen that before a morpheme beginning with a simple onset, a final high vowel is realized as a secondary articulation on an adjacent prevocalic consonant, ${ }^{9}$ while a final low vowel deletes. Vowel transposition or deletion is driven by a prohibition against the final vowel of a morpheme occurring in an open syllable (see Hume, 1997). Under the assumption that complex syllable margins are prohibited, syllabifying the initial consonant of a consonant cluster as coda of the preceding syllable, as in ko.nim.de.ri /koni mderi/, not only avoids a complex consonant cluster, but places the final vowel of the first morpheme in a closed syllable thereby avoiding deletion or transposition. Note once again that the across-morpheme syllabification of vowel-final forms before a cluster is identical to the output of consonant-final forms which undergo metathesis before a consonant cluster, and $\mathrm{C}$-final forms that remain unchanged before a $\mathrm{CV}$-initial morpheme; that is, VC.CV.

(8)a.

cf. b.

$\begin{array}{ll}\text { /koni + mderi/ } & \text { konimderi } \\ \text { /mutu + vnua/ } & \text { mutuvnua } \\ \text { /ai + vlakar/ } & \text { aivlakra } \\ \text { /loi + llalutun/ } & \text { loillalutnu } \\ \text { /samela + ttenan/ } & \text { samelattenna } \\ \text { /spou + ttenan/ } & \text { spouttenna } \\ \text { /rai + lavan/ } & \text { ralyavna } \\ \text { /samela + mota/ } & \text { samelməta }\end{array}$

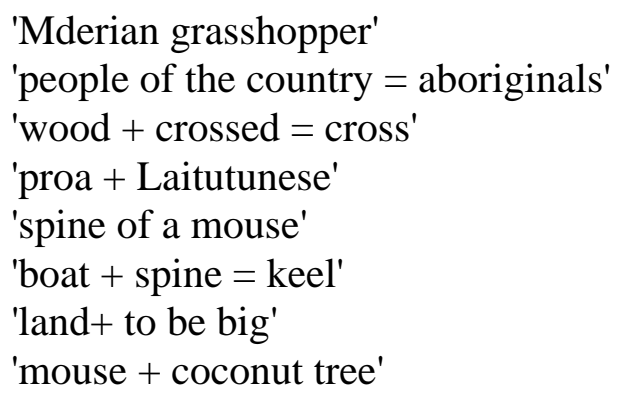

Drawing on the observation that tautosyllabic consonant clusters are avoided, stated as the constraint *COMPLEX in (9) (based on Prince \& Smolensky 1993), we are able to provide a unified account of the patterns observed above.

(9) *COMPLEX: tautosyllabic consonant clusters are prohibited.

The role of *COMPLEX in the derivation of consonant-final forms occurring before a cluster is illustrated in (10). As can be seen, candidate (a) shows morpheme boundaries aligned with syllable boundaries. This, however, produces a complex onset, thus violating * CompLEX. Conversely, in the actual surface form in (c), metathesis has applied to the final consonant and vowel of the first morpheme, accompanied by

9 When the following vowel is also high, the first high vowel deletes. This is in accordance with a general prohibition in the language against tautosyllabic sequences of [+high]. (see Hume, 1997, for further discussion and analyses). 
syllabification of the initial consonant as coda of the preceding syllable. Given that syllable and morpheme boundaries are misaligned, this form not only violates LINEARITY, but also CRISP EDGE (based on Itô \& Mester 1994), given in (11). The crucial ranking of *COMPLEX over CRISP EDGE and LINEARITY predicts the correct output. Note that simply metathesizing the final consonant and vowel of the first morpheme without resyllabification as in (b) is insufficient; a complex syllable margin remains. Consequently, while a violation of LINEARITY may lead to metathesis, as in (c), this is not a sufficient condition; higher constraints such as *COMPLEX must also be satisfied. Thus, in Leti it is better to reverse the linear ordering of segments and misalign syllable and morpheme boundaries than to tolerate a complex syllable margin.

\begin{tabular}{|l|l|l|c|c|c|}
\hline & & UR: ulit+prai & $*$ COMPLEX & CRISP EDGE & LINEARITY \\
\hline & a. & u.lit. pra.i & $* !$ & & \\
\hline & b. & ul.ti. pra.i & $* !$ & & $*$ \\
\hline r & c. & ul.tip.ra.i & & $*$ & $*$ \\
\hline
\end{tabular}

(11) CRISP EDGE: Morpheme and syllable boundaries are aligned.

This same account extends easily to the derivation of vowel-final forms occurring before a consonant cluster. Note that in candidate (b), switching the linear ordering of segments is ruled out. This follows straightforwardly from our analysis above since while candidates (b) and (c) both incur violations of CRISP EDGE, metathesis leads to an additional violation of LINEARITY thus rendering output (b) less optimal than the actual surface form in (c). (See section 3 for related discussion.)

\begin{tabular}{|l|l|l|c|c|c|}
\hline & & UR: lopu mderi & $*$ COMPLEX & CRISP EDGE & LINEARITY \\
\hline & a. & lo.pu. mde.ri & $* !$ & & \\
\hline & b. & lop. mu.de.ri & & $*$ & $* !$ \\
\hline c & c. & lo.pum. de.ri & & $*$ & \\
\hline
\end{tabular}

For consonant-final forms occurring before a morpheme beginning with a simple onset, our analysis correctly predicts no change. Three candidates are considered in (13). In (a), the correct surface realization, the first morpheme remains essentially the same as in the input. *COMPLEX rules out syllabifications which yield complex margins, as in (b), while metathesis in (c) adds a violation of LINEARITY rendering it less optimal than candidate (a). ${ }^{10}$

10 While not crucial to the analyses in this paper, candidates (b) and (c) are also ill-formed due to the observation that the final vowel of the initial morpheme occurs in an open syllable. Formulated as $* \mathrm{~V}$ in Hume 1997, this highly ranked constraint forces, among other things, vowel deletion in forms such as /samela nura/ [samel nura] 'mouse + coconut tree'. 
(13)

\begin{tabular}{|c|c|l|c|c|c|}
\hline & & UR: lout de & $*$ COMPLEX & CRISP EDGE & LINEARITY \\
\hline a & a. & lo.ut. de & & & \\
\hline & b. & lo.u. tde & $* !$ & $*$ & \\
\hline & c. & lo:.tu. de & & & $* !$ \\
\hline
\end{tabular}

Thus, through the crucial ranking of *COMPLEX over both CRISP EDGE and LINEARITY, we obtain a unified account of the observed patterns above. Not only is metathesis before a complex cluster correctly predicted to occur, but this same ranking selects resyllabification in vowel-final forms occurring before a cluster, and no change for consonant-final morphemes occurring before a simple onset.

\subsubsection{Consonant Sequences: Phrase-initially}

To complete our examination of consonant clusters in Leti, it is worthwhile pointing out that while consonant clusters are prohibited phrase-internally as above, in absolute phrase-initial position they may occur, as shown in (14a). When the initial consonant of the sequence is of a higher sonority grade than the second, the morpheme-initial consonant is realized as syllabic, as shown in (14b). ${ }^{11}$

\begin{tabular}{|c|c|c|c|}
\hline 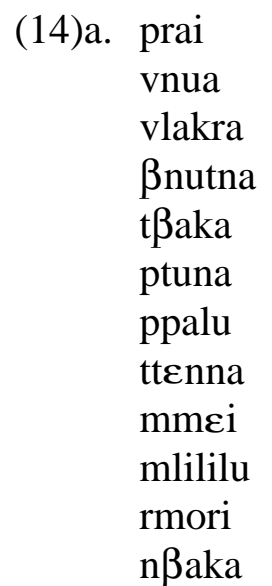 & $\begin{array}{l}\text { 'prai' } \\
\text { 'country' } \\
\text { 'crossed' } \\
\text { 'iron' } \\
\text { 'we ask' } \\
\text { 'star' } \\
\text { 'index finger' } \\
\text { 'spine' } \\
\text { 'table' } \\
\text { 'sour' } \\
\text { 'they live' } \\
\text { 'he asks' }\end{array}$ & 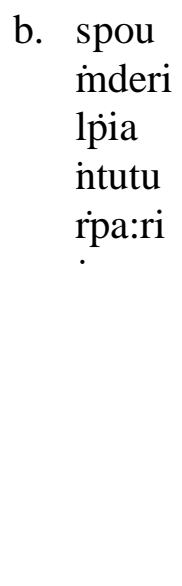 & $\begin{array}{l}\text { 'kind of boat' } \\
\text { 'Mderi' } \\
\text { 'sago-palm' } \\
\text { 'he points' } \\
\text { 'they pay' }\end{array}$ \\
\hline
\end{tabular}

As the sequencing of consonants in (14) illustrates, Leti consonants divide into two sonority grades, with continuants $(\beta \mathrm{s})$ and sonorant consonants $(\mathrm{m} \mathrm{n} \mathrm{lr}$ ) forming one sonority level, and the stops ( $\mathrm{p} \mathrm{t} \mathrm{k}$ ) forming a lesser degree of sonority. ${ }^{12}$ Based on this division, the sequencing of consonants within the Leti syllable is consistent with Jespersen's (1904, 1950) SONORITY PRINCIPLE, stated in (15).

11 The claim that the first consonant is realized as syllabic is based on the intuitions of van Engelenhoven (1994), a native speaker of Leti, rather than on independent phonological evidence. For example, there is no contrast between syllabic and nonsyllabic consonants in Leti.

12 While the inherent sonority of sonorant consonants is higher than that of the continuants, phonologically they pattern as one class thus leading to their grouping as a single sonority grade. See Hume \& Odden, 1996 for a reanalysis of sonority in terms of Impedance which allows for a straightforward means of grouping these two types of sounds together as one class in terms of their patterning in sonorityrelated phenomena. 
SONORITY PRINCIPLE (Jespersen, 1950:131)

Between a given sound and the peak are only found sounds of the same, or a higher, sonority class.

In sequences of consonants which satisfy the SONORITY PRINCIPLE, such as ptuna, a consonant cluster appears phrase-initially, as illustrated in (16). As can be seen, the correct output in (a) violates *COMPLEX. While, in principle, inserting a vowel or deleting a consonant could be used as a means of avoiding a complex cluster, consonant deletion and default vowel epenthesis are never observed in the language. Hence, the faithfulness constraints DEP-V/MAX-C (McCarthy \& Prince, 1995) must be more highly ranked than *COMPLEX, as illustrated in (b) and (c). DEP penalizes vowel insertion, while MAX penalizes consonant deletion, as stated in (17).

\begin{tabular}{|c|c|c|c|c|c|}
\hline & & I: \#\#ptuna & DEP-V/MAX-C & CONSPEAK & *COMPLEX \\
\hline 10 & a. & ptuna & & & $*$ \\
\hline & b. & tuna & $* !$ & & \\
\hline & c. & pVtuna & $* !$ & & \\
\hline & d. & ptuna & & $* !$ & \\
\hline
\end{tabular}

(17) DEP-V: a vowel in the output has a correspondent in the input.

MAX-C: a consonant in the input has a correspondent in the output.

Realizing the initial consonant as syllabic, as shown in (16d), could also serve to avoid a cluster yet, as noted above, this strategy is only observed when the output would otherwise result in a sonority sequencing violation. Therefore, in general, syllabic consonants in Leti are avoided, which, following Rosenthall 1994, can be accounted for by the constraint CONSPEAK, in (18).

(18) ConsPeaK (Rosenthall, 1994; see also Prince \& Smolensky, 1993 on HNUC): Consonants are not syllable peaks.

A further means of avoiding a cluster would be to metathesize the first vowel and adjacent consonant, as in *putna. I set aside discussion of this candidate for the moment but will return to this issue in section 3 where it will be shown that the avoidance of this type of metathesis falls out of a more general prohibition against the intrusion of a vowel between tautomorphemic segments.

With respect to the realization of initial consonants as syllablic, a straightforward account is obtained by incorporating Jespersen's SONORITY PRINCIPLE (SP) into the ranking. Crucially, as shown in (19), SP outranks CONSPEAK, expressing the observation that it is more highly valued in Leti for a consonant to surface as syllabic than to violate the SONORITY PRINCIPLE. 
(19)

\begin{tabular}{|l|l|l|c|c|c|}
\hline & & I: \#\#spou & SP & CONSPEAK & *COMPLEX \\
\hline & a. & spou & $* !$ & & $*$ \\
\hline & b. & spou & & $*$ & \\
\hline
\end{tabular}

This analysis extends easily to our previously motivated account of phrase-medial metathesis. As shown in (20b), realizing the initial consonant of the second morpheme as syllabic is ruled out by the ranking of CONSPEAK over LINEARITY. Note that this ranking falls out by transitivity from the independently motivated rankings of CONSPEAK $>*$ COMPLEX and *COMPLEX $>$ LINEARITY. Thus, it is better to avoid a complex syllable margin by metathesis, than for a consonant to surface as syllabic.

(20)

\begin{tabular}{|c|c|l|c|c|c|c|}
\hline & & UR: ulit+prai & SP & CONSPEAK & *COMPLEX & LINEARITY \\
\hline & a. & u.lit. pra.i & & & $* !$ & \\
\hline & b. & u.lit. p.ra.i & & $* !$ & & \\
\hline$\square$ & c. & ul.tip.ra.i & & & & $*$ \\
\hline
\end{tabular}

For consonant sequences which violate the SONORITY PRINCIPLE, we predict the same result, as shown in (21).

(21)

\begin{tabular}{|c|c|l|c|c|c|c|}
\hline & & UR: maran + mderi & SP & CONSPEAK & *COMPLEX & LINEARITY \\
\hline & a. & maran.mderi & $* !$ & & $*$ & \\
\hline & b. & maran.m.deri & & $* !$ & & \\
\hline c. & c. & marnam.deri & & & & $*$ \\
\hline
\end{tabular}

\subsubsection{Summary}

Our account thus far has shown avoidance of complex syllable margins to be the driving force behind metathesis. Not only does this approach account for metathesis, but it also extends in a straightforward manner to the analysis of vowel-final forms occurring before a consonant cluster and consonant-final forms occurring before a simple onset. Further, while consonant clusters may, under certain conditions, occur utterance-initially, our analysis correctly rules out such syllabification phrase-internally.

\subsection{The Avoidance of Onsetless Syllables}

We turn now to cases of metathesis occurring before a morpheme-initial /CVV/ sequence, where, as can be seen in (22), the final vowel and consonant of the initial morpheme reverse positions. In addition to metathesis, the initial vocoid of the second morpheme is realized as a glide, e.g. uk.ram.wa.ni. Metathesis is these cases, I argue, is motivated by the need to avoid an onsetless syllable.

$$
\begin{array}{lll}
\text { /puoras + liora / } & \mathrm{p}^{\mathrm{w}} \text { orsalyora } & \text { 'door + seaside = seaside gate' } \\
\text { /ukar + muani/ } & \text { ukramwani } & \text { 'finger + man = middle finger' }
\end{array}
$$




\section{HUME/METATHESIS}

Support for this approach comes from the observation that, metathesis aside, the avoidance of onsetless syllables serves to motivate a number of additional phonological changes in Leti. For example, as a means of resolving vowel hiatus, an unstressed high vowel may be realized as a secondary articulation on an adjacent prevocalic consonant, as shown in (23), both within and across morpheme boundaries.

\begin{tabular}{|c|c|c|}
\hline$/ \operatorname{tani}+$ arat $/$ & $\tan y^{a r t a}$ & 'soil + edge' \\
\hline /tultulu + enu/ & tultul ${ }^{\mathrm{W}}$ enu & 'hat + turtle' \\
\hline /avieras/ & avyersa & 'rice' \\
\hline /niosir/ & nyosri & 'public' \\
\hline /na-ptiali/ & naptyali & 'it is fluid' \\
\hline /duona/ & dwona & 'basil' \\
\hline
\end{tabular}

If the following vowel is high, the prevocalic high vowel deletes in accordance with a prohibition against tautomorphemic sequences of [+high] in Leti, e.g. /ari + ulit/ arulti 'ray + tail'.

Further, when a morpheme beginning with an onsetless syllable is preceded by a consonant-final morpheme, the final consonant syllabifies as onset of the following syllable. Note that the vowel preceding the consonant is realized as a secondary articulation or deleted, as above. ${ }^{13}$

$$
\begin{aligned}
& \text { /na + tikil + erun/ ntik.lyer.nu '3p.sg.+kick+downwards' } \\
& \text { /maun + oriori/ ma:.n }{ }^{\mathrm{w}} \text { o.ry } \text { o.ri 'bird + buffalo' } \\
& \text { /rain + iskola/ ra:.nis.ko.la 'blouse + school' } \\
& \text { /urun + ipar/ ur.nip.ra 'breadfruit + slice' }
\end{aligned}
$$

\begin{tabular}{|c|c|}
\hline /rai+aan/ & raya:na \\
\hline /kokkoi+aan/ & kəkkəya:na \\
\hline $\begin{array}{l}\text { /au+rei+ear/ } \\
\text { /isauaa/ }\end{array}$ & $\begin{array}{l}\text { arweye:ra }^{\text {w }} \\
\text { isawaa }\end{array}$ \\
\hline
\end{tabular}

Avoiding onsetless syllables by glide formation is also attested, as in the following examples where an unstressed intervocalic high vowel is realized as a glide.

$$
\begin{aligned}
& \text { 'king + diminutive = prince' } \\
& \text { 'child + dim. = baby' } \\
& \text { '1st p., to pull, dispersed=I pull apart' } \\
& \text { 'crocodile' }
\end{aligned}
$$

To account for the pervasive tendency to avoid onsetless syllables in Leti, I draw on the constraint ONSET, given in (26).

ONSET: A syllable has an onset.

Accounting for metathesis before a /CVV/-initial morpheme is straightforward once ONSET is integrated into the analysis. This is illustrated in (27) for input /ukar muani/. As can be seen, candidate (a), which most closely resembles the input, is ill-formed since the second morpheme contains an onsetless syllable. ${ }^{14}$ In the actual surface form in (e),

13 As noted previously, transposition or deletion of the vowel is forced by a requirement in the language that the final vowel of a morpheme may not occur in an open syllable phrase-medially.

14 For simplicity, I omit violations of ONSET incurred by the initial syllable in [ukar]. As is perhaps evident from this, vowel-initial words do occur in absolute phrase-initial position although a glottal stop 
the final consonant and vowel of the first morpheme metathesize, with the morphemeinitial consonant syllabifying as the coda of the preceding syllable, identical to that seen in (12) above. Thus, the optimal metathesis form once again incurs violations of both CRISP EDGE and LINEARITY. All alternative means of resolving the onset violation are non-harmonic. For example, as shown in (b), gliding the high vowel would result in a complex syllable margin, thus violating our previously motivated constraint *COMPLEX. Deleting the high vowel (or following vowel) would also avoid an onsetless syllable. However, vowel deletion is used only as a last resort in Leti when strategies which would otherwise preserve the vowel fail (Hume, 1997). Thus, in this account, vowel deletion is judged less optimal than metathesis, in (e). Finally, preserving the vowel as a secondary articulation would also suffice to avoid an onsetless syllable, as well as satisfy the prohibition against complex syllable margins. Yet, given that this form fails to surface we can conclude that secondary articulation formation, formalized as the constraint *COMPSEG in (28), is less preferable to metathesis.

\begin{tabular}{|l|l|l|c|c|c|c|c|c|}
\hline & $\begin{array}{l}\text { UR: } \\
\text { ukar + muani }\end{array}$ & *COMPLEX & $\begin{array}{c}\text { MAX } \\
\text {-V }\end{array}$ & ONSET & $\begin{array}{c}\text { *COMP } \\
\text { SEG }\end{array}$ & $\begin{array}{c}\text { CRISP } \\
\text { EDGE }\end{array}$ & LINEARITY \\
\hline & a. & ukar muani & & & $* !$ & & & \\
\hline & b. & ukar mwani & $* !$ & & & & & \\
\hline & c. & ukar mani & & $* !$ & & & & \\
\hline & d. & ukar m ${ }^{\text {wani }}$ & & & & $* !$ & & \\
\hline er & e. & ukram wani & & & & & $*$ & $*$ \\
\hline
\end{tabular}

(28) *COMPSEG (Padgett, 1995): a segment may not have more than one place specification.

This analysis extends simply to vowel-final forms occurring before a /CVV/-initial sequence, as in $/ v a t u+$ liaar/va.tul.ya: $r a$ 'stone + sole = prop'. Once again, avoidance of an onsetless syllable forces modification of the input resulting in an across-morpheme syllabification identical to that observed in $(27 \mathrm{e})$.

(29)

\begin{tabular}{|l|l|l|c|c|c|c|c|c|}
\hline & $\begin{array}{l}\text { UR: } \\
\text { vatu + liaar }\end{array}$ & *COMPLEX & $\begin{array}{c}\text { MAX } \\
\mathbf{- V}\end{array}$ & ONSET & $\begin{array}{c}* \text { COMP } \\
\text { SEG }\end{array}$ & $\begin{array}{c}\text { CRISP } \\
\text { EDGE }\end{array}$ & LIN \\
\hline & a. & vatu lia:ra & & & $* !$ & & & \\
\hline & b. & vatu lya:ra & $* !$ & & & & & \\
\hline & d. & vatu la:ra & & $* !$ & & & & \\
\hline & e. & vaut lya:ra & & & $* !$ & $*$ & & $*$ \\
\hline f. & vatul ya:ra & & & & & $*$ & \\
\hline
\end{tabular}

It is worthwile noting that while onset satisfaction forces metathesis in consonant-final forms, metathesis is ruled out in vowel-final forms such as (29e) since it would produce a

can generally be heard preceding the vowel. I assume that this is a phonetic effect since glottal stop plays no role in the phonology. 


\section{HUME/METATHESIS}

'new' onsetless syllable. Instead, realizing the high vowel as a glide, with misalignment of morpheme and syllable edges is sufficient to generate the correct output.

\subsection{Compensatory Lengthening Effects}

One set of metathesis forms that has yet to be discussed concerns those in which metathesis is accompanied by a compensatory lengthening effect, as the examples in (30) illustrate. When the morpheme-final vowel is transposed by metathesis, the remaining stem vowel is realized as long.

$$
\begin{array}{lll}
\text { /Buar + spou/ } & \text { Bu:raspou } & \text { 'mountain }+ \text { boat }=\text { schooner mountain' } \\
\text { /maun + ppuna/ } & \text { ma:nuppuna } & \text { 'bird + nest' } \\
\text { /maun + tpunan/ } & \text { ma:nutpunan } & \text { 'bird + throat' }
\end{array}
$$

Compensatory lengthening effects are not exclusive to metathesis but occur whenever the final vowel of a / VVC/ morpheme is transposed or deleted. For example, in (31a) the final high vowel of a morpheme is realized as a secondary articulation on the following consonant, while in (b), the high vowel deletes. In both cases, the preceding stem vowel is realized as long.

$$
\begin{array}{lll}
\text { a. /maun + oriori/ } & \text { ma: }{ }^{\mathrm{w}} \text { or }^{\mathrm{y}} \text { ori } & \text { 'bird + buffalo' } \\
\text { b. /rain + iskola/ } & \text { ra:niskola } & \text { 'blouse + school' }
\end{array}
$$

The observation that the preceding stem vowel is realized as long follows from the view that vowel transposition or deletion affects only a vowel's segmental content, not its underlying moraic structure. Thus, when a vowel shifts by metathesis, for example, it is only the melody that changes position, with its mora remaining in its original (input) position. As shown in (32), this involves preservation of the underlying mora of the final stem vowel. The remaining stem vowel is thus realized phonetically as bimoraic.
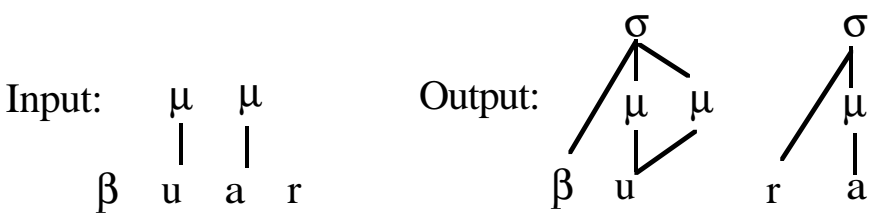

Note also in (32) that while the input contains two moras, three are present in the output. In other words, a mora has been inserted to accomodate the metathesized vowel. To account for mora insertion, I draw on the DEP family of constraints (McCarthy \& Prince, 1995). Specifically, DEP- $\mu$ penalizes the presence of a mora in the output which is not present in the input.

(33) DEP- $\mu$ : a mora in the output has a correspondent in the input. 
As tableau (34) illustrates, preservation of the input vowel's mora prevails in the correct surface form in (c). Failure to parse the underlying stem-internal mora in (b) incurs a violation of MAX- $\mu$ which renders this candidate ill-formed. ${ }^{15}$

\begin{tabular}{|c|c|c|c|c|c|c|}
\hline & & UR:ßuar + spou & *COMPLEX & MAX- $\mu$ & DEP- $\mu$ & LINEARITY \\
\hline & a. & $\beta$ u.ar. spo.u & $* !$ & & & \\
\hline & b. & ßu.ras.po.u & & $* !$ & $*$ & $*$ \\
\hline 咩 & c. & $\beta u$ :.ras.po.u & & & $*$ & $*$ \\
\hline
\end{tabular}

Note that with respect to metathesis forms such as [ultiprai] /ulit prai/ seen above, it is not possible to determine whether or not the mora of the metathesized vowel is preserved in such cases. While one might assume that the mora of the metathesized vowel is preserved on the coda consonant [1], we have no way to test this assumption. Nonetheless, whether or not the mora is preserved in such cases has no effect on the analysis proposed above.

\subsection{Phrase-final Metathesis}

Thus far we have focussed exclusively on phrase-internal metathesis which serves to satisfy syllable structure conditions. A second type of metathesis also occurs in the language, affecting consonant-final forms in phrase-final position. Relevant examples appear in (35), with metathesis most easily observed by comparing a phrase-final form with its phrase-medial counterpart before a simple onset.

\begin{tabular}{|c|c|c|c|c|}
\hline$U R$ & \multicolumn{2}{|c|}{ Phrase-finally } & \multicolumn{2}{|l|}{$C f \cdot{ }_{\ldots} \# C V$} \\
\hline /urun/ & [urnu] & 'breadfruit' & [urun məa] & 'Moanese breadfruit' \\
\hline /mesar/ & [mesra] & 'teacher' & [mesar lavna] & 'teacher, big' \\
\hline /lout/ & [lo:tu] & 'servant' & [lout de] & 'servant, once' \\
\hline /ßuar/ & [ßu:ra] & 'mountain' & [ $\beta$ uar lavna] & 'highest mountain' \\
\hline /laar/ & [la:ra] & 'squamosa' & [la:r wa:ra] & 'squamosa root' \\
\hline /polias/ & [poli:sa] & 'police' & [polias se] & 'the policeman (I know of)' \\
\hline
\end{tabular}

Relevant to this type of metathesis is the observation that in phrase-final position, all morphemes end in a vowel. For consonant-final forms, as just illustrated, the final vowel and consonant of a morpheme change positions with accompanying compensatory lengthening effects when relevant. Conversely, for vowel-final forms, the phrase-final surface form is essentially identical to the underlying form, as in (36).

15 An alternative interpretation of candidate (b) would be to assume that a mora is not inserted on the metathesized vowel. Rather, the underlying mora of the transposed vowel also shifts to morpheme-final position. Under this interpretation, candidate (b) would not incur violations of either Max- $\mu$ or Dep- $\mu$. To my knowledge, no cases of metathesis are attested which involve transposition of both segmental and prosodic structure; only segmental content is affected. To rule out this interpretation we may assume an undominated constraint which guarantees the integrity of moraic structure of the input. I leave the exact formulation of this constraint for further consideration. My thanks to Robert Poletto for bringing this issue to my attention. 


\section{HUME/METATHESIS}

\begin{tabular}{lllll} 
Phrase-finally & \multicolumn{2}{l}{ cf. Phrase-medially } & \\
rai & 'land' & ralyavna & /rai+lavan/ & 'land+ to be big=continent' \\
lopu 'dophin' & lopd $^{\text {wo }}$ & /lopu+do/ & 'dolphin, then' \\
tultulu 'hat' & tultulwenu & /tulu+tulu+enu/16 & 'hat + turtle=kind of hat'
\end{tabular}

Before proceding with the account of this type of metathesis, a few comments concerning phrasing in Leti may prove useful. The goal of this section is not to provide an in-depth treatment of the conditions which govern phrasing in Leti. This is beyond the scope of the present paper and requires further study. Rather, of relevance to the present discussion is the observation that phrase-final metathesis differs from phrase-medial metathesis in that it is not motivated by general syllable well-formedness conditions but rather by phrasal requirements.

The sequencing of words or morphemes into phrases is determined by both syntactic and morphological considerations, with the shape of a particular morpheme depending on whether it is in phrase-final or phrase-medial position. This is exemplified by the alternation lalavan3 lalavna in (37), where syntactic considerations on phrasing come into play (phonological phrase boundaries as \{\} and relevant syntactic phrasal boundaries are marked by []).

$$
\begin{array}{ll}
\begin{array}{l}
\text { /asu lalavan davar de/ } \\
{[\{\text { aslwalavandavarde }\}]}
\end{array} & \text { 'dog + big + very + once' } \\
& \text { 'the very big dog once' } \\
\text { /asu lalavan iatiat de/ } & \text { 'dog + big + bad + once' } \\
{[[\{\text { aslwalavna }\}]\{\text { yatyatde }\}]} & \text { 'the big bad dog once' }
\end{array}
$$

Phrasing often serves a morphological function, as in (38), where phrasing distinctions are evidenced by both phonological and semantic differences.

$$
\begin{aligned}
& \text { /na vali vatu la eni/ } \\
& \{\text { nvali }\}\{\text { vatu }\}\{\text { la }\}\{\text { eni }\} \\
& \left\{\text { nvalvyatlwa }^{\mathrm{w}}\{\text { eni }\}\right.
\end{aligned}
$$

'3rd sg. + turn + stone + go + sand'

'He turns the stone to the beach.'

'He somehow turns a stone to the beach.'

These distinctions may be used to convey, among other things, the notions of definiteness/indefiniteness, transitivity/intransitivity, or to form causatives or verbal nouns (see van Engelenhoven 1994, 1995).

The observation that all phrases must end in a vowel may be viewed as a type of boundary marker used to signal the end of a syntactically or morphologically determined phrase. In terms of formalism, we may account for this by means of the alignment constraint, given in (39), which states that the right edge of a phrase is aligned with a vowel. ALIGN-PHRASE is thus a member of the family of NOCODA constraints.

ALIGN-PhrASE: (P-Phrase, Rt; Vowel, Rt)

Align the right edge of a phonological phrase with a vowel.

16 This form illustrates one type of reduplication in the language, with the reduplicant and base adhering to the same constraints as other phrase-medial forms. See Muller 1996 for further discussion and analyses of Leti reduplication within an OT approach. 
Phrase-final metathesis follows straightforwardly from the ranking of ALIGN-PHRASE over LINEARITY, as shown in (40).

\begin{tabular}{|l|l|l|c|c|}
\hline & & I: kunis\#\# & ALIGN-PH & LINEARITY \\
\hline & a. & kunis & $* !$ & \\
\hline$\square$ & b. & kunsi & & $*$ \\
\hline
\end{tabular}

Forms with a compensatory lengthening effect receive the same account, as shown in (41), with MAX- $\mu$ coming into play to rule out ill-formed candidates such as (c).

(41)

\begin{tabular}{|l|l|l|c|c|c|c|}
\hline & & UR: lout\#\# & ALIGN-PH & ONSET & MAX- $\mu$ & LINEARITY \\
\hline a & a. & lo:tu & & & & $*$ \\
\hline & b. & lout & $* !$ & $*$ & & \\
\hline & c. & lotu & & & $* !$ & $*$ \\
\hline
\end{tabular}

While default vowel epenthesis would also serve to satisfy the phrasal requirement by providing a final vowel for consonant-final forms, this strategy is not attested in the language. Rather, rearrangement of underlying elements via metathesis is selected.

\subsection{Summary}

Thus far, we have observed two types of metathesis in Leti. One which is driven by general syllable structure conditions of the language, and one which is motivated by phrasal requirements governing the shape of a morpheme. In the following section, two issues relating to metathesis are explored: the observation that metathesis systematically affects only the final segments of a morpheme, and the observation that the reordering of only two segments within a word is attested in Leti.

\section{Constraining Metathesis}

Recall from section 2.2 that the avoidance of an onsetless syllable provides the impetus to modify a given form by metathesis. For example, to account for forms such as [ukramwani], repeated in (42), ONSET is crucially ranked above both CRISP EDGE and LINEARITY. For simplicity, violations of ONSET incurred by the initial syllable of the first morpheme are omitted.

\begin{tabular}{|l|l|l|c|c|c|}
\hline & & $\begin{array}{l}\text { UR: } \\
\text { ukar + muani }\end{array}$ & ONSET & $\begin{array}{c}\text { CRISP } \\
\text { EDGE }\end{array}$ & LINEARITY \\
\hline & a. & ukar muani & $* !$ & & \\
\hline a & b. & ukram wani & & $*$ & $*$ \\
\hline
\end{tabular}

What this ranking fails to rule out, however, is forms such as *ulitpari from underlying /ulit prai/ in which segments of the second morpheme metathesize. Reversing 
the order of segments in the second form would not only successfully avoid an initial complex cluster, but it would also serve to resolve vowel hiatus within the second morpheme. Furthermore, metathesis of the consonant and vowel of the second morpheme results in an otherwise well-formed sequence in Leti, cf. /uran tani/ $\rightarrow$ uran tani 'worm + soil'. However, as we have seen, metathesis systematically affects the final consonant and vowel of the first morpheme only, as in the correct output, ultiprai. In fact, as shown in (43), our analysis thus far incorrectly predicts candidate (b) to surface. (Incorrectly selected surface forms are indicated by ' $\sigma$ ', while the actual surface form is shown by ' $\checkmark$ '.)

\begin{tabular}{|c|c|l|c|c|c|c|}
\hline & & UR:ulit+prai & $*$ COMPLEX & ONSET & CRISP EDGE & LINEARITY \\
\hline & a. & u.lit. pra.i & $* !$ & $*$ & & \\
\hline$\sigma$ & b. & u.lit. pa.ri & & & & $*$ \\
\hline$\checkmark$ & c. & ul.tip.ra.i & & $* !$ & $*$ & $*$ \\
\hline
\end{tabular}

The actual surface form in (c) involves metathesis of the final consonant and vowel of the first morpheme, leaving vowel hiatus of the second morpheme intact.

The crucial difference between (b) and (c), I would suggest, relates to the output position of the metathesized vowel. In (43c), the vowel shifts to the outer edge of the first morpheme, as shown in (44a), while in (43b), the vowel intrudes between two underlyingly contiguous segments, as in (44b).

a.

$\mathrm{u} \quad \mathrm{l} \quad \mathrm{i} \quad \mathrm{t} \longrightarrow[\mathrm{ulti}]$ b.

$\mathrm{p} \_\mathrm{r} \quad \mathrm{a} \quad \mathrm{i} \rightarrow *[$ pari $]$

This distinction is precisely that captured in the correspondence constraint OCONTIGUITY, developed in the study of vowel epenthesis in Kenstowicz 1994 (see also McCarthy \& Prince, 1995). As McCarthy \& Prince (1995:371) note, "O-Contig rules out internal epenthesis: the map xz -> xyz violates O-Contig, but xy -> xyz does not." While not explicit in McCarthy \& Prince's formulation in (45), it is assumed here, as in Kenstowicz 1994, that the relevant domain for the evaluation of contiguity relations is the morpheme. Thus, inserting a vowel between tautomorphemic segments is prohibited, while inserting it at the edge of a morpheme is not.

O-CONTIGUITY (McCarthy \& Prince, 1995)

The portion of $\mathrm{S}_{2}$ standing in correspondence forms a contiguous string.

Thus, C/V metathesis may be viewed as a type of vowel epenthesis and as such, is subject to the same restrictions. Support for this view comes from the observation that in both epenthesis and metathesis, an additional mora (or V-slot) may occur in the output. Our examination of metathesized forms displaying compensatory lengthening effects in Leti confirms this claim. That is, while underlying /lout/ contains two moras, the metathesized alternant lo:tu contains three. However, metathesis differs from vowel epenthesis in that contiguity relations among the metathesizing vowel and segments adjacent to this vowel in the input are also affected. For example, metathesis in cases 
such as /kunis/ -> kunsi could also be viewed as incurring a violation of O-CONTIGUITY since in the input $/ \mathrm{n} /$ and /i/ are contiguous, while on the surface, they are separated by [s]. This suggests that in Leti, only vowel insertion is penalized by O-CONTIGUITY, expressed in the modified version of the constraint in (46).

O-CONTIGUITY-V

A contiguous string in the input may not be separated by a vowel in the output.

By assuming a vowel contiguity constraint separate from one which refers to consonants, we predict that consonant and vowel epenthesis may behave differently within a single language with respect to O-CONTIGUITY. That is, while a language may not permit vowels to intrude between segments, consonant

s may, or vice versa. Maltese confirms this prediction (Hume, 1994, 1996; Aquilina, 1959): [t]-epenthesis occurs only intermorphemically, between suffix and stem, e.g.

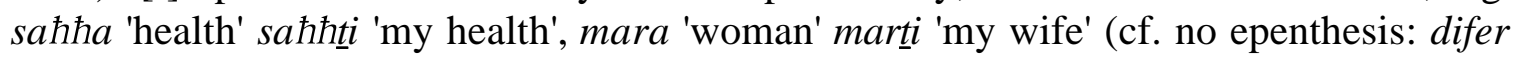
'nail' difri 'my nail', isem 'name' ismi 'my name'), while vowel epenthesis may occur between tautomorphemic root consonants: midinba *midnba 'sinner' (cf. no epenthesis: mitbna 'straw heap' ).

The failure of metathesis to affect non-morpheme-final segments can therefore be accounted for by ranking O-CONTIGUITY-V above ONSET, as in (47). ${ }^{17}$ Given our previously motivated ranking of ONSET above CRISP EDGE and LINEARITY, by transitivity, O-CONTIGUITY-V will also outrank CRISP EDGE and LINEARITY.

\begin{tabular}{|c|c|c|c|c|c|c|c|}
\hline & & I:urun+prai & $*$ COMPLEX & O-CONTIG-V & ONSET & $\begin{array}{c}\text { CRISP } \\
\text { EDGE }\end{array}$ & LINEARITY \\
\hline & a. & u.run. pra.i & $* !$ & & $*$ & & \\
\hline & b. & u.run. pa.ri & & $* !$ & & & $*$ \\
\hline & c. & ur.nup.ra.i & & & $*$ & $*$ & $*$ \\
\hline
\end{tabular}

Likewise, metathesis into a following morpheme is also correctly ruled out, rendering LINEARITY essentially superfluous in such cases (cf. (12)).

(48)

\begin{tabular}{|l|l|l|c|c|c|}
\hline & & I: lopu + mderi & O-CONTIG-V & $\begin{array}{c}\text { CRISP } \\
\text { EDGE }\end{array}$ & LINEARITY \\
\hline a & a. & lopum.deri & & $*$ & \\
\hline & b. & lop muderi & $* !$ & $*$ & $*$ \\
\hline
\end{tabular}

Consequently, while metathesis is a strategy used pervasively in Leti to resolve potentially ill-formed words, which segments may metathesize is highly constrained: a metathesized vowel may only shift to the outer edge of a morpheme.

17 For related comments, see footnote 18. 


\section{Linearity and Gradiency}

In Leti, only a single consonant and vowel metathesize in a given word; in no case do we observe multiple reorderings of segments. Thus, while in order to satisfy the phrasal vowel-final requirement, /ukar/ 'finger' is realized as $u k r a$, it is never the case that additional segments metathesize, e.g. *urka. The reason for this is simple: there is no motivation in the language for an additional reordering of segments. For metathesis to apply at all, there must be some motivation to force change. Otherwise, the output form which most closely resembles the input will be most faithful. For phrase-final metathesis, this involved satisfaction of the vowel-final phrasal requirement while for phrase-medial metathesis, the avoidance of complex clusters and onsetless syllables provided the requisite motivation. Although in terms of syllable contact, output *urka may be preferable to $u k r a$ since the coda of the first syllable is higher in sonority than the onset of the following syllable (see Clements, 1990; Vennemann, 1988), syllable contact considerations do not play an active role in modifying inputs in Leti. Thus, it is more important to maintain the linear ordering of segments of the input, than to modify the order to satisfy requirements of syllable contact, for example. Consequently, for the linear ordering of segments to change, the constraint LINEARITY must be crucially ranked below some constraint $\mathbb{C}$ which forces modification of the input. Otherwise, precedence relations remain unchanged.

Yet, what actually prevents additional reorderings? That is, how do we account for the observation that minimal changes in the ordering of segments are always preferred, all else being equal? A straightforward account is available by assuming that violations of LINEARITY are gradiently evaluated: each precedence reversal incurs a violation of LINEARITY. For example, as illustrated in (49) for the input /ukar/, changing the order of the final consonant and vowel in (a) results in one precedence reversal (indicated by *). Reordering the final consonant and vowel in addition to the two consonants yields two precedence reversals. Adding to this a reordering of the initial vowel and consonant, one more reversal occurs. Under the assumption that a minimal change is preferred, output (a) will be evaluated as optimal.

$$
\begin{aligned}
& \text { Precedence relations: } \\
& / \mathrm{u}_{1} \mathrm{k}_{2} \mathrm{a}_{3} \mathrm{r}_{4} / \quad 1<2,2<3,3<4 \text {; by transitivity: } 1<3,1<4,2<4 \\
& \text { a. } \mathrm{u}_{1} \mathrm{k}_{2} \mathrm{r}_{4} \mathrm{a}_{3} \quad 1<2,2<4, * 4<3 \\
& \text { b. } \mathrm{u}_{1} \mathrm{r}_{4} \mathrm{k}_{2} \mathrm{a}_{3} \quad 1<4, * 4<2,2<3 ; * 4<3 \text { (by transitivity) } \\
& \text { c. } \mathrm{r}_{4} \mathrm{u}_{1} \mathrm{k}_{2} \mathrm{a}_{3} \quad * 4<1,1<2,2<3 ; * 4<2, * 4<3 \text { (by transitivity) }
\end{aligned}
$$

This is expressed in tableau (50) where candidates (c-d) are shown to incur a greater number of LINEARITY violations than the optimal output in (b). 


\begin{tabular}{|l|l|l|c|c|}
\hline & & UR:ukar 'finger' & $*$ ALIGN-PHRASE & LINEARITY \\
\hline & a. & ukar & $* !$ & \\
\hline b & b. & ukra & & $*$ \\
\hline & c. & urka & & $* * !$ \\
\hline & d. & ruka 18 & & $* * ! *$ \\
\hline
\end{tabular}

An important consequence of the claim that violations of LINEARITY are gradiently evaluated, in conjunction with the view that metathesis only occurs when there is motivation for change, is that we predict a language in which the optimal output may incur more than a single violation of LINEARITY. To illustrate, consider the hypothetical input $/ \mathrm{C}_{1} \mathrm{~V}_{2} \mathrm{C}_{3} \mathrm{~V}_{4} \mathrm{C}_{5} /$ in (70). Let us assume two constraints $\mathrm{C}_{\mathrm{a}}$ and $\mathrm{C}_{\mathrm{b}}$. Candidate (a), which corresponds to the input, is ill-formed due to a violation of $\mathrm{C}_{\mathrm{a}}$. This violation is avoided by reordering the final segments of the word, identical to the metatheses seen in Leti above. However, metathesizing the final segments is insufficient since the new output in (b) violates constraint $C_{b}$. Both constraints $C_{a}$ and $C_{b}$ can be satisfied by an additional reordering, as shown in (c). Thus, not only do the final consonant and vowel metathesize, but the two consonants switch positions as well. Consequently, although candidate (c) incurs two violations of LINEARITY, it is predicted to surface given the crucial ranking of $\mathrm{C}_{\mathrm{a}}$ and $\mathrm{C}_{\mathrm{b}}$ above LINEARITY.

\begin{tabular}{|l|l|l|c|c|c|}
\hline & & $\mathrm{I}_{0} \mathrm{C}_{1} \mathrm{~V}_{2} \mathrm{C}_{3} \mathrm{~V}_{4} \mathrm{C}_{5}$ & $\mathrm{C}_{\mathbf{a}}$ & $\mathrm{C}_{\mathbf{b}}$ & LINEARITY \\
\hline & a. & $\mathrm{C}_{1} \mathrm{~V}_{2} \mathrm{C}_{3} \mathrm{~V}_{4} \mathrm{C}_{5}$ & $* !$ & & \\
\hline & b. & $\mathrm{C}_{1} \mathrm{~V}_{2} \mathrm{C}_{3} \mathrm{C}_{5} \mathrm{~V}_{4}$ & & $* !$ & $*$ \\
\hline & c. & $\mathrm{C}_{1} \mathrm{~V}_{2} \mathrm{C}_{5} \mathrm{C}_{3} \mathrm{~V}_{4}$ & & & $* *$ \\
\hline
\end{tabular}

This prediction is borne out by metathesis in the Costanoan language Mutsun (Okrand, 1977). As the examples in (52) illustrate, the nominal thematic plural suffix shows two alternants: -mak occurs after noun stems ending in a consonant or glide, $-\mathrm{kma}$ occurs after noun stems ending in a vowel.

18 Given that Onset is ranked above Linearity in Leti, *[ruka] would be predicted to surface, despite the observation that two violations of Linearity are incurred. However, absolute word-initial segments resist metathesis in Leti; a word-initial onsetless sequence is never resolved by shifting a consonant into initial position. Rather, as noted above, it is consistently word-final segments that undergo metathesis. This observed asymmetry may relate to perceptual salience. Since, according to Cutler, Hawkins and Gilligan 1985, lexical access is generally achieved on the basis of the initial part of the word, salient information tends to occur at the beginning. Moreover, beginnings of words tend to be particularly robust and able to resist phonological processes (Hall, 1992). Two observations bearing on metathesis cross-linguistically are consistent with this view: first, metathesis generally affects morpheme-final segments; and second, cases of metathesis in which a word-initial vowel and following consonant change positions are rare (see Hume, 1995 for related discussion). With respect to the formal means of ruling out initial metathesis in a form such as *[ruka] /urak/, we may draw on the correspondence constraint (LEFT) ANCHOR which requires that the element on the left edge of the input corresponds to the element on the left edge of the output (McCarthy \& Prince 1993). In Leti, ANCHOR would necessarily be more highly ranked than Onset. 


\section{HUME/METATHESIS}

(52)

$\begin{array}{lll}\text { ru:k } & \text { 'string' } & \text { ru:kmak } \\ \text { wimmah } & \text { 'wing' } & \text { wimmahmak } \\ \text { kahhay } & \text { 'head louse' } & \text { kahhaymak } \\ \text { ?innis } & \text { 'son' } & \text { Tinnismak } \\ \text { rukka } & \text { 'house' } & \text { rukkakma } \\ \text { to:te } & \text { 'deer, meat' } & \text { to:tekma } \\ \text { sinni } & \text { 'child' } & \text { sinnikma } \\ \text { relo } & \text { 'clock' } & \text { relokma }\end{array}$

A similar type of metathesis involves the locative suffix which also displays two alternants -tak 3 -tka, depending on whether the stem ends in a consonant or vowel, respectively (Okrand 1977:154).

$\begin{array}{lll}\text { Purkan } & \text { 'mortar' } & \text { ?urkantak } \\ \text { si(:)t } & \text { 'tooth, teeth' } & \text { sittak } \\ \text { ?anyis } & \text { 'other (one)' } & \text { ?anyistak } \\ \text { tarah } & \text { 'sky' } & \text { tarahtak } \\ \text { ?ama } & \text { 'body, person' } & \text { ?amatka } \\ \text { pire } & \text { 'world, land' } & \text { piretka } \\ \text { ?orco } & \text { 'ear' } & \text { ?orcotka } \\ \text { ?isšu } & \text { 'hand" } & \text { Pisšutka }\end{array}$

Given the -tak 3 -tka alternation in (53) where only the final consonant and vowel switch positions, we might also expect the nominal thematic suffix to show the alternation *-mak3-mka. Instead, however, not only is the ordering of the final consonant and vowel reversed, but the ordering of the two suffixal consonants also changes yielding kma3 mak. Of relevance in understanding why the consonants of this suffix change position is the observation that the labial consonant systematically occurs in onset position, e.g. ru:k.mak, ruk.kak.ma. This is consistent with the observation that, in general, coda [m] is avoided in the language, supported by Okrand's observation (p.71) that "only / $\mathrm{r} \mathrm{w} \mathrm{y/are} \mathrm{attested} \mathrm{as} \mathrm{final} \mathrm{sonorants} \mathrm{of} \mathrm{monosyllables."} 19$ The coda constraint, ${ }^{*} \mathrm{~m}_{\text {coda }}$, prohibiting the occurrence of $[\mathrm{m}]$ in coda position ,captures this observation.

To account for the mak3 $\mathrm{kma}$ alternation, I assume non-crucially that the suffix has the underlying form $/ \mathrm{mak} /$. Note that the analysis to follow is also consistent with assuming $/ \mathrm{kma} /$ as the input. As illustrated in (54) for vowel-final noun stems, the input form violates a constraint which I refer to simply as $\mathbb{C}$. I leave the specifics of this constraint open at the present time although speculate that it is related to foot structure given that penults are typically heavy in Mutsun. Of relevance to our discussion is the observation that while simply metathesizing the final consonant and vowel in (b) will satisfy constraint $\mathbb{C}$, the output is ill-formed due to a violation of the constraint against coda $[\mathrm{m}]$. Readjustment of the ordering of the two consonants in (c) satisfies both higher ranked constraints, even though the optimal form incurs two violations of LINEARITY.

19 Note that while $/ \mathrm{m} /$ does occur word-finally in polysyllabic forms, Okrand records an epenthetic vowel when preceding a consonant-initial word, as in [makam ${ }^{\partial}$ rittcapu] 'you [pl.] are speaking amongst yourselves.' Thus, in word-final position as well, $[\mathrm{m}]$ is released into a vowel, albeit epenthetic. 
(54)

\begin{tabular}{|l|l|l|c:c|c|}
\hline & & I: relo + mak & $\mathbf{C}$ & $* \mathbf{m}_{\text {]coda }}$ & LINEARITY \\
\hline & a. & re.lo.mak & $* !$ & & \\
\hline & b. & re.lom.ka & & $* !$ & $*$ \\
\hline r $*$ c. & re.lok.ma & & & $* *$ \\
\hline
\end{tabular}

For comparison, the derivation of the suffix following consonant-final stems is provided in (55). The optimal form in (a) with no metathesis best satisfies syllable structure requirements in Mutsun which, like Leti, prohibit complex syllable margins.

\begin{tabular}{|l|l|l|cc:c|c|}
\hline & & I: $\mathrm{ru}: \mathrm{k}+\mathrm{mak}$ & $*$ COMPLEX & C & $* \mathbf{m}_{\text {]coda }}$ & LINEARITY \\
\hline a & a. & ru:k.mak & & & \\
\hline & b. & ru:k.mka & $* !$ & & $*$ \\
\hline & c. & ru:k.kma & $* !$ & & $* *$ \\
\hline
\end{tabular}

Mutsun thus provides an apt example illustrating the gradient nature of LINEARITY. Not only is metathesis observed in the language, but the optimal form may incur more than one violation of the constraint as a means of satisfying more highly ranked constraints.

Note that while assuming that violations of LINEARITY are gradiently violated, I know of no synchronic case of metathesis in which the optimal form shows more than two violations. For example, hypothetical examples in which a complete array of segments within a word are rearranged are not attested. This is perhaps not surprising since drastic reorderings would surely inhibit word recognition.

\section{Comparison with a Nonlinear Rule-based Approach}

In this final section I consider two alternative accounts of Leti metathesis: a nonlinear rule-based approach and a templatic approach. As I will attempt to show, consideration of these alternative accounts in contrast to a Correspondence Theoretic approach leads to the conclusion that the latter is to be preferred.

In nonlinear phonology, one means of accounting for consonant/vowel metathesis draws on the view that metathesis is the product of a series of phonological operations, formalized as rules of, for example, epenthesis, deletion and spreading (see e.g. Besnier, 1987; Hume, 1990). Along these lines, the derivation of phrase-final metathesis in Leti could take the following form. Taking the input /kunis/, for example, phrase-final metathesis would involve the insertion of a vowel slot in phrase-final position. In addition, the final vowel of the stem delinks from its prosodic affiliation. By universal association conventions (Haraguchi, 1977; Clements \& Ford, 1979; Pulleyblank, 1986), the floating vocalic melody maps onto the epenthetic V-slot in a feature-filling manner. 
(56)

\begin{tabular}{|c|c|c|c|c|c|}
\hline UR: & $\mathrm{k}$ & $\mathrm{u}$ & $\mathrm{n}$ & $\mathrm{i}$ & $\mathrm{S}$ \\
\hline a. Epenthesis & $\mathrm{k}$ & $\mathrm{u}$ & $\mathrm{n}$ & $\mathrm{i}$ & $\mathrm{S}$ \\
\hline b. Deletion & $\mathrm{k}$ & $\mathrm{u}$ & $\mathrm{n}$ & $\begin{array}{l}\varnothing \\
{[\mathrm{i}]}\end{array}$ & $\mathrm{S}$ \\
\hline c. Spreading & $\mathrm{k}$ & $\mathrm{u}$ & $\mathrm{n}$ & [i] & $\mathrm{S}$ \\
\hline SR: & {$[\mathrm{k}$} & $\mathrm{u}$ & $\mathrm{n}$ & $\mathrm{s}$ & i] \\
\hline
\end{tabular}

Similar to the CT account of metathesis presented further above, it can be assumed in (56) that consonants and vowels are ordered with respect to one another underlyingly. Accounting for the observation that the vowel melody /i/ spreads across an intervening consonant, as in stage (56c), is nonproblematic under the assumption that the features of consonants and vowels are sufficiently disjoint (cf. McCarthy, 1989). For example, by adopting a model of feature organization such as that proposed in Clements \& Hume 1995, a vowel melody is able to spread across an intervening consonant nonproblematically, as in (57). In this model, the place features of consonants are dominated by C-place while those of vowels are dominated by V-place. Metathesis is thus represented as spreading the Vocalic node of the vowel, dominating both place and aperture, to the inserted prosodic position to the right. The Vocalic node delinks from its original affiliation. Given that major class features are noncontrastive for vowels, we may assume that features such [+sonorant], [+approximant] which form part of the vowel's root node, are assigned by default.

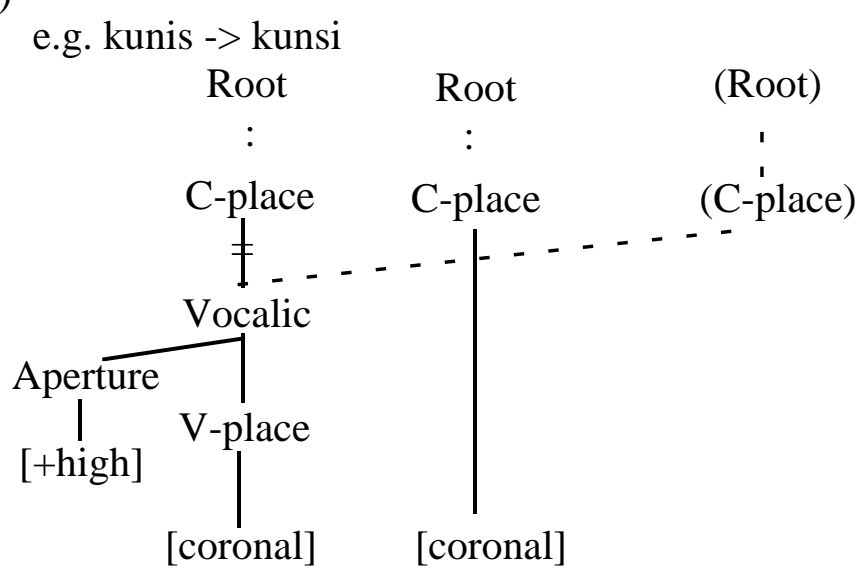

Implicit in both (56) and (57) is the assumption that metathesis is the product of more than one rule or operation. Hence, the multiple-operation approach results in the disembodiment of metathesis as a phonological process, thus rejecting the view of metathesis as a basic operation type on a par with, for example, assimilation or dissimilation. That is, unlike assimilation, which is formalized as spreading, and dissimilation (deletion), which is characterized as delinking, there is no single operation 
available in nonlinear phonology capable of expressing the process whereby two segments reverse positions.

One reason for reducing metathesis to a product of operations as opposed to assigning it its own unique rule formalism stems from the commonly held view that metathesis is marginal as compared to processes such as assimilation, for example. In both sound change and synchronic phonological systems, assimilation is widespread, while metathesis on the other hand, though often regular, may be limited in its scope, affecting only a subset of forms or morphological classes of a given language. As suggested by Kiparsky (1995), this asymmetry may stem from the observation that assimilation tends to be production (articulatorily) driven, while metathesis is perception (acoustically) driven. Articulatory-driven processes, in contrast to perceptually-driven ones, generally develop due to physiological constraints on the vocal tract apparatus and, as a result, tend to be more automatic and hence, widespread. The observation that dissimilation is also perceptual in nature (Ohala, 1981) is consistent with this view since, as Kiparsky (1995) notes, it also occurs with less regularity than assimilation in both sound change and synchronic systems. Yet, while dissimilation is characterized as a single operation in nonlinear phonology, on a par with assimilation, there is no single operation available to express metathesis. Both assimilation and dissimilation constitute distinct phonological processes and each have unique expressions in the theory. Since metathesis is equally distinct in nature from both assimilation and dissimilation, there is no a priori reason to assume that metathesis should not also be given a unique formalism within the theory. In addition, as seen with respect to Leti above, metathesis can be regular and pervasive within a given phonological system.

An additional reason for rejecting metathesis as a primitive operation type goes back to its characterization in linear SPE formalism (Chomsky \& Halle 1968). As shown in (58), metathesis was represented by a context-free rewrite rule, which simply stipulates a change in the ordering of segments.

$$
\begin{array}{lllllllllllll}
/ \mathrm{k} & \mathrm{u} & \mathrm{n} & \mathrm{i} & \mathrm{s} / \\
1 & 2 & 3 & 4 & 5 & \rightarrow 1 & 2 & 3 & 5 & 4
\end{array}
$$

Unrestricted rewrite rules of this type are extremely powerful; essentially any operation, attested or not, can be formulated. The fact that linear formalism was inadequate to represent metathesis is not a sufficient argument for rejecting metathesis as a privative operation, however. Deletion also required an unrestricted rewrite rule, yet it is unlikely that one would doubt the existence of deletion as a phonological process. ${ }^{20}$ Thus, the problem, I would suggest, lies with the formalism used to express metathesis; it does not necessarily entail the nonexistence of metathesis as a primitive operation type.

In contrast to a nonlinear rule-based approach, within Correspondence Theory, incorporating the constraint LINEARITY into the theory allows for the treatment of metathesis as a single operation; segments, i.e. root nodes with all subordinate features, switch positions, characterized by a violation of LINEARITY, a constraint which is independently required in the theory to assure the input ordering of segments on the surface in non-metathesis cases. Consequently, not only is metathesis provided with a

20 I am grateful to David Odden for reminding me of this point. 
unique formalism in CT (a violation of LINEARITY), we acknowledge the existence of metathesis as a distinct process.

A further problem relating to an approach in which metathesis is treated as the product of more than one rule is that we predict the independence of each rule in the phonology of the language in question (see e.g. Hume, 1990 on metathesis in Maltese). For example, given the rules of epenthesis and deletion in the account of Leti metathesis in (56), we predict each of these rules to operate independently in the grammar. In Leti, however, there is no independent evidence for vowel epenthesis. A new prosodic position is only added in cases of metathesis. To the extent that these rules can not be independently motivated, we weaken our end-product view of metathesis.

Even more problematic for an account of metathesis which draws on the non-linear operations of spreading and delinking are cases in which the segments involved differ in features which are not maximally disjoint in the representation. Recall from (57) that this is non-problematic for an account of consonant/vowel metathesis when the appropriate model of feature organization is assumed. Such is not the case in all types of metathesis, however. Consonant/consonant metathesis provides numerous examples which prove problematic for an spreading/delinking account of metathesis.

Consider, for example, metathesis in Deg, a Gur language of west-central Ghana, where the labial sonorants $/ \mathrm{m}, \mathrm{w} /$ metathesize with a following $/ \mathrm{r} /$ (Crouch, in prep). As illustrated in (59.a), the formation of the plural of class 1 nouns typically involves the addition of the suffix /rI/,/-re/ or /-ri/, according to vowel harmony. However, when the stem ends in $/ \mathrm{m} /$ or $/ \mathrm{w} /$ (see (60) below), metathesis occurs.

\begin{tabular}{|c|c|c|c|}
\hline (59) & Singular & Plural & \\
\hline a. & [d^ǵgú] & [d^ǵgú!rı] & 'grasscutter' \\
\hline & [ná́] & [nań!rı] & 'back' \\
\hline b. & [nom̀] & [nəŕ!mI] & 'scorpion' \\
\hline & [dè̀] & [deŕ!mi] & 'house' \\
\hline & [nam̀] & [naŕ!mi] & 'type of tree" \\
\hline & [doì] ] & [doŕ!mi] & 'sleep' \\
\hline & [baì] & [baŕ!mi] & 'hard part of fruit" \\
\hline
\end{tabular}

Some Deg verbs also form the plural by the addition of the suffix /-rI/ (the final vowel is dropped before the suffix), as in (60.a). Once again, if the final consonant of the verb is $/ \mathrm{m} /$ or $/ \mathrm{w} /$, metathesis occurs and the labial occurs as the onset of the final syllable.

\begin{tabular}{|c|c|c|c|}
\hline (60) & Singular & Plural & \\
\hline a. & [vvg̀c] & [vug̀rı] & 'to divine (many times)' \\
\hline b. & [sı̀̀e] & [sır̀̀wI] & 'to die' \\
\hline & [laìve] & [lar̀wi] & 'to catch" \\
\hline & [ù̀e] & [ừmi] & 'to clench fist" \\
\hline
\end{tabular}

Distributional facts of Deg reveal that labials never occur in coda position, either preconsonantally or word-finally. Metathesis is therefore consistent with this pattern, which may be accounted for by positing a coda constraint which prohibits labials in coda position. Within a spreading/delinking approach to metathesis, however, providing a 


\section{HUME/METATHESIS}

unified rule of metathesis to account for the observed facts is problematic. For reference, I provide the language's consonantal inventory in (61).

(61) Inventory of consonants:

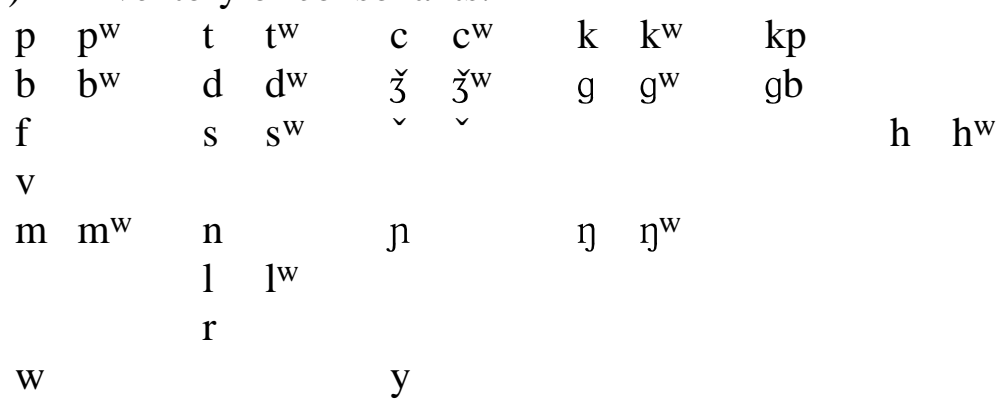

To illustrate the problems associated with such an account, I will assume as a starting point, the feature specifications in (62). For simplicity, only the specifications of (nonlabialized) sonorant consonants are given. Place features as well as [nasal] and [lateral] are assumed non-crucially to be privative, while [sonorant], [approximant] and [continuant] are binary.

$(62)$

\begin{tabular}{|l|l|l|l|l|l|l|l|l|}
\hline & $\mathrm{m}$ & $\mathrm{w}$ & $\mathrm{r}$ & $\mathrm{l}$ & $\mathrm{n}$ & $\mathrm{n}$ & $\mathrm{y}$ & $\mathrm{y}$ \\
\hline sonorant & + & + & + & + & + & + & + & + \\
\hline approximant & - & + & + & + & - & - & + & - \\
\hline nasal & $\bullet$ & & & & $\bullet$ & $\bullet$ & & $\bullet$ \\
\hline lateral & & & & $\bullet$ & & & & \\
\hline continuant & - & + & - & - & - & - & + & - \\
\hline labial & $\bullet$ & $\bullet$ & & & & & & \\
\hline coronal & & & $\bullet$ & $\bullet$ & $\bullet$ & $\bullet$ & $\bullet$ & \\
\hline posterior & & & & & & $\bullet$ & $\bullet$ & \\
\hline dorsal & & & & & & & & $\bullet$ \\
\hline
\end{tabular}

As illustrated in (62), all sonorant consonants are distinct underlyingly. With respect to the three consonants involved in metathesis, $/ \mathrm{m} /$ contrasts with $/ \mathrm{r} /$ on the basis of place features and [approximant, nasal]. Further, /w/ contrasts with /r/ in terms of [continuant] and place. Assuming this feature specification, characterizing metathesis as a unitary rule in the language requires spreading the feature values of [approximant, nasal, continuant] and place. Since [approximant], as a major class feature, is generally considered to form part of the root node (Clements \& Hume, 1995, based on McCarthy, 1988), the root nodes of the segments in question are required to spread, as below. However, doing so would inevitably result in crossed association lines (Goldsmith, 1976) since the root nodes are linked by association line to identical superordinate nodes (syllable, or C-slots).

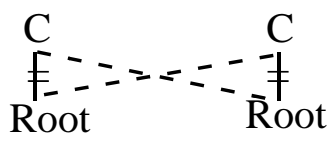


In order to avoid this problem, we might attempt more minimally specified segments. By eliminating [approximant] and [continuant], for example, we are still able to distinguish among sonorants in the language, as in (64).

(64)

\begin{tabular}{|l|l|l|l|l|l|l|l|l|}
\hline & $\mathrm{m}$ & $\mathrm{w}$ & $\mathrm{r}$ & $\mathrm{l}$ & $\mathrm{n}$ & $\mathrm{n}$ & $\mathrm{y}$ & $\mathrm{\eta}$ \\
\hline sonorant & + & + & + & + & + & + & + & + \\
\hline nasal & $\bullet$ & & & & $\bullet$ & $\bullet$ & & $\bullet$ \\
\hline lateral & & & & $\bullet$ & & & & \\
\hline labial & $\bullet$ & $\bullet$ & & & & & & \\
\hline coronal & & & $\bullet$ & $\bullet$ & $\bullet$ & $\bullet$ & $\bullet$ & \\
\hline posterior & & & & & & $\bullet$ & $\bullet$ & \\
\hline dorsal & & & & & & & & $\bullet$ \\
\hline
\end{tabular}

In this scenario, $/ \mathrm{m} /$ is distinguished from $/ \mathrm{r} /$ on the basis of [nasal] and place, while $/ \mathrm{w} /$ contrasts with / $\mathrm{r}$ / on the basis of place alone. As is evident, accounting for metathesis is not possible by spreading a single feature. Both [nasal] and place must spread. Under the assumption that [nasal] is linked to the root node, we are once again required to spread the root nodes in order to represent metathesis as a unified process. Note that if only the place features were to switch, we would incorrectly predict the outcome of metathesizing $/ \mathrm{m}+\mathrm{r} /$ to be $*[\mathrm{nw}]$. Invoking alternative underspecifications are equally problematic.

Similar problems are encountered with any case of consonant/consonant metathesis in which the segments involved differ in terms of major class and subordinate features. Additional examples include metathesis in Mutsun, Elmolo and Rendille. With respect to Mutsun, it will be recalled that metathesis involves the nominal thematic plural suffix which alternates between -mak and -kma (see (52)). In this case, the two metathesizing consonants differ not only in place features (labial vs. dorsal) but in terms of nasality and major class features.

Similar observations hold for metathesis in the Cushitic language Elmolo. In this case, metathesis occurs in the plural formation of some nouns (Zaborsky, 1986). In general, the plural is formed by the addition of the suffix /-o/, as the forms in (65) reveal.

$\begin{array}{lll}\text { Singular } & \text { Plural } & \\ \text { kárris } & \text { kárrís-o } & \text { 'cheek' } \\ \text { kúnuf } & \text { kúnúf-ó } & \text { 'fingernail' } \\ \text { ek } & \text { ek-o } & \text { 'fire' } \\ \text { nan̂n } & \text { nan̂̀-o } & \text { 'harpoon' } \\ \text { ô̂ } & \text { ố-o } & \text { 'tree' } \\ \text { ser } & \text { ser̂-o } & \text { 'rain, cloud' }\end{array}$

When the medial or final consonant of a bisyllabic noun is a liquid, the vowel of the last syllable elides. As shown in (66.b), metathesis occurs in nouns of this group when the final consonant is a liquid. ${ }^{21}$ Again, the consonants which metathesize differ in both place and major class features.

21 While in the majority of cases provided by Zaborsky (1988), /k/ occurs in the stem, I assume this is accidental. 


\section{HUME/METATHESIS}

(66) a

$\begin{array}{llll}\text { a. } & \text { ilik } & \text { ilk-o } & \text { 'tooth' } \\ & \text { cilik } & \text { cilk-o } & \text { 'foot" } \\ & \text { ělem } & \text { ělm-o } & \text { 'sheep' } \\ \text { b. } & \text { tikir } & \text { tiŕk-o } & \text { 'catfish' } \\ & \text { deker } & \text { deŕk-o } & \text { 'horn' } \\ & \text { mukul } & \text { mulk-o } & \text { 'iron' }\end{array}$

Metathesis in Rendille, a language spoken in the southern Marsabit district in north Kenya (Oomen, 1981; Sim, 1981), presents a similar example. ${ }^{22}$ As discussed in Sim 1981, metathesis is observed in words when, due to vowel deletion, an otherwise nonpermissible consonant sequence is created, as shown in (67).

(67)

a. 'sleep'

'see'

'shiver'

'mother'

'cloth'

'skinbag'

'armpit'

'eat!'

b. cf.

'tear (n.)'

'shoulder blade'

'charcoal'

$\begin{array}{ll}\text { 'you }(s g) / s h e^{\prime} \\ \text { udurte } \\ \text { agarte } & \\ \text { hamarte } & \\ \text { sg. pl. } & \\ \text { abar } & \text { arbo } \\ \text { dafar } & \text { darfo } \\ \text { ugar } & \text { urgo } \\ \text { bahab } & \text { babћo } \\ \text { aham } & \text { amha }\end{array}$

'we'

'I/he'

udurre urde

agarre arge

hamarre harme

Metathesis positions an obstruent or pharyngeal fricative in onset position which may be treated as a strategy to enhance the perceptual salience of these segments (see Hume, in prep). Of relevance is the observation that once again the pairs of metathesizing consonants may differ not only in terms of place features, but also in terms of major class features.

Representing each of the cases of consonant/consonant metathesis above is problematic for an account which characterizes metathesis as spreading and delinking. To aptly represent metathesis we must assume that the operation occurs at the level of the root node. That is, the entire segments switch positions. This is problematic within a nonlinear account in which spreading is constrained by the inviolable no line crossing convention. Conversely, in our proposed Correspondence Theoretic account of metathesis above, LINEARITY may be violated and when it is, metathesis of entire segments occurs.

Turning more directly to a comparison of the account of Leti presented in sections (24) with that of a rule-based approach, a further advantage of the former relates to the observation that the motivation behind metathesis is explicitly integrated into the analysis. As the analyses of Leti revealed, it is specifically satisfaction of the constraints *COMPLEX, ONSET and ALIGN-PHRASE which force a change in the linear ordering of

22 My thanks to Sam Rosenthall for bringing this case to my attention. 
segments, i.e. a violation of LINEARITY. Conversely, in a rule-based approach, the motivation for metathesis is absent from the analysis. Rather, metathesis results from a series of rules, with each rule expressing only the operation involved in the change. Given that a CT account expresses not only the change which a given form undergoes but, in addition, the motivation behind such a change, our account elucidates to a greater extent the nature of metathesis.

Finally, since in terms of formalism, a rule-based account of the Leti facts requires recourse to both rules and constraints while a CT account draws only on constraints, the latter can be viewed as simpler. Although a variety of examples could be given to illustrate the need for constraints in a rule-based account of Leti, perhaps the most straightforward case concerns high vowel deletion. As noted above, an unstressed prevocalic high vowel is typically realized as a secondary articulation on an adjacent prevocalic consonant, as shown in (68a). The vowel fails to surface, however, just in case the following vowel is also high, as in (68b). While the rule of secondary articulation formation could be formulated in such a way as to incorporate the requirement, through feature specification, that the following vowel must be [-high], a more insightful account takes into account the pervasive cross-linguistic tendency to avoid adjacent identical melodies, formalized as the OBLIGATORY CONTOUR PRINCIPLE. The specific instantiation of the OCP constraint relevant to the Leti facts prohibits tautosyllabic sequences of [+high], a similar cooccurrence constraint to that observed in languages such as Malay (Onn 1976) and Korean (Kang 1996).
(68)a. $/ \operatorname{tani}+$ arat/
tanyarta
'soil + edge'
b. /ari + ulit/
arulti
'ray + tail'

By incorporating the OCP [+high] constraint into the analysis, not only do we elucidate the motivation behind high vowel deletion, but in addition, are able to omit seemingly arbitrary feature specifications from the rule of secondary articulation. Yet, by doing so, two types of formalism are utilized in phonological theory: rules and constraints. Given that our CT account of Leti draws only upon constraints, we restrict the formal machinery required, resulting in a simpler analysis.

While both the rule-based account in (75) as well as the CT analysis of metathesis presented further above assume linear ordering in the input, an alternative analysis of the Leti facts would be to assume that consonants and vowels are unordered with respect to one another underlyingly (cf. McCarthy, 1989; van der Hulst \& van Engelenhoven, 1994). In this approach, there is no specific 'rule(s)' of metathesis; instead, the surface syllable patterns which emerge result from the mapping of underlying segments to relevant syllable positions, guided by universal and language specific conditions on association. Such an approach is problematic, however, since syllabification in Leti is not always predictable. For example, both VCVC and CVCV words are attested, e.g. /apun/ 'stomach', /uran/ 'worm', /urun/ 'breadfruit' vs./ruma/'house', /riva/'lap', /mata/ 'eye'. Similarly, words of the shape VCV and CV.V form minimal pairs, e.g. lenu/ 'turtle', /neu/ 'to creep'. Maintaining the position that consonants and vowels are unordered with respect to one another underlyingly might be achieved through the use of prosodic templates. However, unlike languages in which templates characterize distinct morphological classes, e.g. Sierra Miwok (Stonham, 1990), templates do not serve such a function in Leti. Hence, each form would need to be lexically marked for its own 
prosodic template and, as a result, there would be little difference between this approach and one which assumes that segments are linearly ordered with respect to one another underlyingly (for related discussion see McCarthy, 1995).

\section{Conclusion}

In this paper metathesis has been shown to be a pervasive and regular process in Leti. Two types of metathesis were identified: one conditioned by a general phrasal requirement and a second conditioned by syllable structure. With respect to the latter, two general conditions provided the impetus for metathesis: *COMPLEX and ONSET. Both reflect the well-attested cross-linguistic tendencies to avoid complex syllable margins and onsetless syllables, respectively. The interaction of these constraints with the correspondence constraint LINEARITY was shown to provide a unified account of a range of phenomena in the language: it predicted metathesis in one set of forms, resyllabification effects in another, and no change in yet another.

While metathesis is pervasive in the language, it was also shown that metathesis is nonetheless constrained; metathesis is systematically limited to the final vowel and consonant of a morpheme. Although metathesis of other segments results in otherwise well-formed sequences, it was demonstrated that by viewing metathesis as a type of vowel epenthesis, these alternate metatheses are correctly ruled out by the constraint $\mathrm{O}$ CONTIGUITY-V. That is, a metathesized vowel may only shift to the edge of a morpheme.

It was further observed that changes in the linear ordering of segments in Leti is minimal; only one instance of metathesis in a given word is possible. By drawing on the claim that violations of LINEARITY are gradiently evaluated, we are able to provide a straightforward account of this observation. Further, the claim that an optimal form may surface with more than a single reordering of segments, as predicted by this account, is supported by metathesis in Mutsun.

The Correspondence Theoretic account of metathesis was argued to be superior to a rule-based account on several grounds. First, by incorporating the constraint LINEARITY into the theory we recognize metathesis as an independent process, distinct from other processes such as assimilation and dissimilation. Second, unlike a rule-based approach we do not predict the independence of each of a series of phonological rules used to account for metathesis. Third, a LINEARITY-based account of metathesis is able to generalize in a straightforward manner to cases of consonant/consonant metathesis, while a nonlinear account of metathesis drawing on the inviolability of No Line Crossing is not. Fourth, a CT account of metathesis integrates both the motivation behind the process and the change observed into the analysis. And finally, a CT account of metathesis may be viewed as simpler in that only one type of formalism (constraints), as opposed to two (rules and constraints), is required to account for the observed facts.

\section{References}

Aquilina, J., 1959. The Structure of Maltese. Malta: The Royal University of Malta. Besnier, Niko, 1987. An Autosegmental approach to metathesis in Rotuman. Lingua 73, 201-223. 
Chomsky, Noam and Morris Halle. 1968. The Sound Pattern of English. New York: Harper and Row.

Clements, G.N., 1990. The Role of the sonority cycle in core cyllabification. In J. Kingston, M. Beckman (eds.), Papers in laboratory phonology 1: Between the grammar and physics of speech, 283-333. New York: CUP.

Clements, G.N. and K.C. Ford, 1979. Kikuyu tone shift and its synchronic consequences. Linguistic Inquiry 10, 179-210.

Clements, G.N. and Elizabeth Hume, 1995. The Internal organization of speech sounds. In John Goldsmith (ed.), Handbook of phonological theory. Blackwell.

Crouch, Marjorie, In preparation. The phonology of Deg. ms. GILLBT, Ghana.

Cutler, A., J.A. Hawkins and G. Gilligan. 1985. The suffixing preference: a processing explanation. Linguistics 23. 723-58.

Goldsmith, John, 1976. An Overview of autosegmental phonology. Linguistic Analysis 2, 23-68.

Hall, Christopher. 1992. Integrating diachronic and processing principles in explaining the suffixing preference. In Morphology and Mind: A unified approach to explanations in linguistics. New York: Routledge.

Haraguchi, S., 1977. The Tone pattern of Japanese: an autosegmental theory of tonology. Tokyo: Kaitakusha.

Hume, Elizabeth, 1990. Metathesis in Maltese: consequences for the strong morphemic plane hypothesis. NELS.

Hume, Elizabeth, 1994a. Front vowels, coronal consonants and their interaction in nonlinear phonology. New York: Garland.

Hume, Elizabeth, 1994b. Metathesis in optimality theory. Paper presented to the Phonetics/Phonology Group, Department of Linguistics, Ohio State University.

Hume, Elizabeth, 1995. Prosodic constraints and C/V metathesis. Proceedings of FLSM 6. Bloomington, Indiana: Indiana University Linguistics Club.

Hume, Elizabeth, 1996. Front vowel, coronal consonant parallels in Maltese. Natural Language and Linguistic Theory 14.

Hume, Elizabeth, in preparation. Towards a formal theory of metathesis. ms. Ohio State University.

Hume, Elizabeth, 1997. Vowel preservation in Leti. Oceanic Linguistics.

Hume, Elizabeth, Jennifer Muller and Aone van Engenhoven, 1996. Initial geminates in Leti. Paper presented at the Mid-Continental Workshop on Phonology 2. University of Illinois, Urbana-Champagne.

Hume, Elizabeth \& David Odden, 1996. Reconsidering [consonantal]. Phonology 13.3.

Itô, Junko and Armin Mester, 1995. Realignment. To appear in R. Kager, H. van der Hulst, W. Zonneveld (eds.), Proceedings of the Utrecht Workshop on Prosodic Morphology. The Hague: Mouton.

Jespersen, O., 1904. Lehrbuch der Phonetik. Leipzig and Berlin.

Jespersen, O., 1950 (5th edition). English phonetics. (translated by B. Jürgensen). Copenhagen: Gyldendalske Boghandel.

Kang, Hyeon-Seok, 1995. Phonological variation and change in Seoul Korean: A sociolinguistic study. $\mathrm{PhD}$ dissertation in progress. Ohio State University.

Kenstowicz, M., 1994. Syllabification in Chukchee: a constraints-based analysis. FLSM 4. 
Kiparsky, Paul, 1995. Phonological basis of sound change. In Goldsmith, John, (ed.), Handbook of phonological theory, 640-670. Oxford: Blackwell.

McCarthy, John, 1988. Feature geometry and dependency: A review. Phonetica 43, 84108.

McCarthy, John, 1989. Linear order in phonological representation. Linguistic Inquiry.

McCarthy, John, 1995. Extensions of faithfulness: Rotuman revisited. ms. UMass, Amherst.

McCarthy, John and Alan Prince, 1993. Prosodic morphology. ms. UMass, Amherst and Rutgers University.

McCarthy, John and Alan Prince, 1994. The emergence of the unmarked: optimality in prosodic morphology. In Mercè Gonzàlez (ed.), Proceedings of the North East Linguistic Society 24, 333-379. Amherst, MA: Graduate Linguistic Student Association.

McCarthy, John and Alan Prince, 1995. Faithfulness and reduplicative identity. To appear in R. Kager, H. van der Hulst, W. Zonneveld (eds.), Proceedings of the Utrecht Workshop on Prosodic Morphology. The Hague: Mouton.

Muller, Jennifer, 1996. Leti reduplication. ms. Ohio State University.

Ohala, John, 1981. The Listener as a source of sound change. In Masek, C.S., R.A. Hendrik, M. F. Miller (eds.), Papers from the parasession on language and behavior, 178-203. Chicago: Chicago Linguistic Society.

Okrand, Marc, 1977. Mutsun grammar. PhD dissertation. University of California. Berkeley.

Oomen, Antoinette, 1981. Gender and plurality in Rendille. Afroasiatic Linguistics 8(1), 35-75.

Onn, Farid, 1976 [1980]. Aspects of Malay phonology and morphology: A generative approach. PhD dissertation. University of Illinois, Urbana-Champaign. [Published by Universiti Kebangsaan Malaysia, Bangi.]

Padgett, Jaye, 1995. Feature classes. In J. Beckman, S, Urbanczyk, L. Walsh (eds.), Papers in optimality theory, University of Massachusetts Occasional Papers 18, 385420. UMass, Amherst: GLSA.

Poletto, Robert, 1993. Metathesis and related processes in Wichita. ms. Ohio State University.

Prince, Alan \& Paul Smolensky, 1993. Optimality theory. ms. Rutgers University and the University of Colorado at Boulder.

Pulleyblank, Douglas, 1986. Tone in lexical phonology. Dordrecht: Reidel.

Rosenthall, Samuel, 1994. Vowel/glide alternation in a theory of constraint interaction. $\mathrm{PhD}$ dissertation. UMass, Amherst.

Sim, Ronald J., 1981. Morphophonemics of the verb in Rendille. Afroasiatic Linguistics 8(1), 1-33.

Smith, Norval, 1984. All change on CV-tier: developments in the history of Aytim and Ayutiri. In Benis, Hans, W.U.S. van Lesses Kloeke (eds.), Linguistics in the Netherlands. Dordrecht: Foris.

Stonham, John, 1990. Current issues in morphological theory. PhD dissertation. Stanford University.

van der Hulst, Harry \& Aone van Engelenhoven, 1994. Metathesis effects in Leti. ms. University of Leiden. 


\section{HUME/METATHESIS}

van Engelenhoven, Aone, 1994. A Description of the Leti language. PhD dissertation. University of Leiden.

van Engelenhoven, Aone, 1995. Indexing the evidence: metathesis and subordination in Leti. ms. University of Leiden.

Vennemann, Theo, 1988. Preference laws for syllable structure. Berlin:

Mouton de Gruyter.

Webb, Charlotte. 1974. Metathesis, PhD. dissertation, University of Texas, Austin.

Zaborsky, Andrzej, 1986. The Morphology of Nominal Plural in the Cushitic

Languages. Institute für Afrikanistik und Agyptologie der Universität Wien. Wien. 